\title{
The homeostasis of iron, copper, and zinc in Paracoccidioides brasiliensis, Cryptococcus neoformans var. grubii, and Cryptococcus gattii: a comparative analysis
}

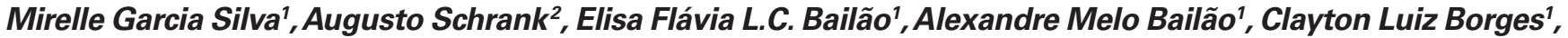 Charley Christian Staats' ${ }^{2}$, Juliana Alves Parente ${ }^{1}$, Maristela Pereira $^{1}$, Silvia Maria Salem-Izacc ${ }^{1}$, Maria José Soares Mendes-Giannini ${ }^{3}$, Rosely Maria Zancopé Oliveira ${ }^{4}$, Lívia Kmetzsch Rosa e Silva², Joshua D. Nosanchuk ${ }^{5,6}$, Marilene Henning Vainstein ${ }^{2}$ and Célia Maria de Almeida Soares ${ }^{1 *}$}

Laboratório de Biologia Molecular, Instituto de Ciências Biológicas, Universidade Federal de Goiás, Goiânia, Goiás, Brazil

2 Laboratório de Biologia Molecular, Centro de Biotecnologia, Universidade Federal do Rio Grande do Sul, Porto Alegre, Rio Grande do Sul, Brazil

${ }^{3}$ Faculdade de Ciências Farmacêuticas, Universidade Estadual Júlio de Mesquista Filho, Araraquara, São Paulo, Brazil

${ }^{4}$ Laboratório de Micologia, Instituto de Pesquisa Evandro Chagas, Fundação Oswaldo Cruz, Rio De Janeiro, Brazil

${ }_{5}$ Division of Infectious Diseases, Department of Medicine, Albert Einstein College of Medicine, Bronx, NY, USA

${ }^{6}$ Department Microbiology and Immunology, Albert Einstein College of Medicine, Bronx, NY, USA

\section{Edited by:}

James A. Fraser, University of

Queensland, Australia

Reviewed by:

James A. Fraser, University of

Queensland, Australia

Dennis J. Thiele, Duke University

School of Medicine, USA

${ }^{*}$ Correspondence:

Célia Maria de Almeida Soares, Laboratório de Biologia Molecular,

Departamento de Bioquímica e Biologia Molecular, Instituto de Ciências Biológicas, Universidade Federal de Goiás, ICB II, Campus II, 74690-900 Goiânia, Goiás, Brazil. e-mail: celia@icb.ufg.br
Iron, copper, and zinc are essential for all living organisms. Moreover, the homeostasis of these metals is vital to microorganisms during pathogenic interactions with a host. Most pathogens have developed specific mechanisms for the uptake of micronutrients from their hosts in order to counteract the low availability of essential ions in infected tissues. We report here an analysis of genes potentially involved in iron, copper, and zinc uptake and homeostasis in the fungal pathogens Paracoccidioides brasiliensis, Cryptococcus neoformans var. grubii, and Cryptococcus gattii. Although prior studies have identified certain aspects of metal regulation in Cryptococcus species, little is known regarding the regulation of these elements in $P$. brasiliensis. We also present amino acid sequences analyses of deduced proteins in order to examine possible conserved domains. The genomic data reveals, for the first time, genes associated to iron, copper, and zinc assimilation and homeostasis in P. brasiliensis. Furthermore, analyses of the three fungal species identified homologs to genes associated with high-affinity uptake systems, vacuolar and mitochondrial iron storage, copper uptake and reduction, and zinc assimilation. However, homologs to genes involved in siderophore production were only found in P. brasiliensis. Interestingly, in silico analysis of the genomes of $P$. brasiliensis $P b 01, P b 03$, and $P b 18$ revealed significant differences in the presence and/or number of genes involved in metal homeostasis, such as in genes related to iron reduction and oxidation. The broad analyses of the genomes of P. brasiliensis, C. neoformans var. grubii, and C. gattii for genes involved in metal homeostasis provide important groundwork for numerous interesting future areas of investigation that are required in order to validate and explore the function of the identified genes and gene pathways.

Keywords: micronutrient homeostasis, pathogenic fungi, infection

\section{INTRODUCTION}

A sufficient supply of iron, copper and zinc is essential for all living and proliferating organisms. In infectious diseases, iron, copper and zinc metabolism are important for both the host and the pathogen, and complex responses in each occur to maintain adequate resources of these elements to preserve homeostasis. Iron, in the form of heme and iron-sulfur clusters, is essential as a cofactor of various enzymes, oxygen carriers, and electron-transfer systems involved in vital cellular functions ranging from respiration to DNA replication (Schaible and Kaufmann, 2004). Copper is a redoxactive metal ion essential for most aerobic organisms, which also serves as a catalytic and structural cofactor for enzymes involved in energy generation, iron acquisition, oxygen transport, and cellular metabolism, among other processes (Kim et al., 2008). Zinc is also a crucial metal, since it is at the catalytic center of numerous enzymes and plays important roles in the functionality of a wide variety of proteins (Van Ho et al., 2002). Mammalian hosts and microbes have developed sophisticated strategies to acquire these metals, even under conditions in which their availability is limited. One of the strategies developed by mammalian hosts to prevent microbial infections is to limit the availability of iron (Weinberg, 2009). Recently, it has been demonstrated that zinc deprivation is a host defense mechanism utilized by macrophages during Histoplasma capsulatum infection (Winters et al., 2010). In addition, the binding of copper to calgranulin $\mathrm{C}$ in human neutrophils could be a mechanism of antimicrobial action (Moroz et al., 2003). In order to counteract these and other host responses, microorganisms employ a range of uptake mechanisms for the targeted acquisition of iron, copper and zinc.

Ferric iron is generally insoluble at physiological $\mathrm{pH}$ in the presence of oxygen. Thus, the common mechanisms of ironassimilation include the reduction of ferric $\left(\mathrm{Fe}^{3+}\right)$ to ferrous $\left(\mathrm{Fe}^{2+}\right)$, 
and solubilization of $\mathrm{Fe}^{3+}$ by binding siderophores (Kornitzer, 2009). The reductive system in fungi is regulated by three different mechanisms. First, a low-affinity iron reductase that functions in iron-rich environments generates $\mathrm{Fe}^{2+}$, which is transported into the cell by a non-specific low-affinity iron permease. Second, a regulated highaffinity ferric reductase operates in low iron conditions, such as those present in a mammalian host. The produced $\mathrm{Fe}^{2+}$ is further oxidized to $\mathrm{Fe}^{3+}$ by a membrane multi-copper-oxidase before being transported across the cell membrane by a high-affinity iron permease. The third mechanism is a non-enzymatic reduction, such as that promoted by 3-hydroxyanthranilic acid (3HAA), which is known to maintain a reduced environment to facilitate the release and sustain the presence of $\mathrm{Fe}^{2+}$ at the fungal membrane until transport occurs (Howard, 1999).

Ferric iron uptake mediated by siderophores is considered a non-reductive high-affinity mechanism by which microorganisms acquire iron. Siderophores are low-molecular weight $\left(M_{\mathrm{r}}<1500\right)$, ferric iron-specific chelators (Neilands, 1993). Microorganisms produce siderophores as scavenging agents in low iron concentration environments in order to supply iron to the cell through the solubilization of extracellular ferric iron. Siderophores are also produced intracellularly for iron storage in most fungi (Matzanke et al., 1987). Siderophores can be classified into three main groups depending on the chemical nature of the moieties donating the oxygen ligands for $\mathrm{Fe}^{3+}$ : catechols, carboxylates and hydroxamates (Miethke and Marahiel, 2007). With the exception of the carboxylate rhizoferrin produced by zygomycetes, the other known fungal siderophores are all hydroxamates (Van der Helm and Winkelmann, 1994). Fungal hydroxamates are derived from the non-proteinogenic amino acid ornithine and can be grouped into four structural families: rhodotorulic acid, ferrichromes, coprogens and fusarinines. Siderophores are named based on their iron-charged forms, existing in the iron-free form of the ligand called desferri-siderophore. Not all fungi produce siderophores. For example, Saccharomyces cerevisiae is not a siderophore producer (Neilands et al., 1987). Similarly, Cryptococcus species and Candida albicans are also unable to produce siderophores. However, these pathogenic fungi can utilize iron bound to siderophores secreted by other species (bacteria and fungi), the xenosiderophores (Howard, 1999). After siderophores are synthesized, they can be utilized intracellularly or secreted to the extracellular medium to solubilize ferric iron. For secreted siderophores, the captured metal of the siderophore-iron complex may be utilized either by reductive iron assimilatory systems or by internalization of the whole complex by specific transporters. In fungi, the uptake of siderophore-iron chelates is accomplished by transporters of the siderophore-iron transporter (SIT) subfamily, previously designated as family 16 of the major facilitator superfamily (MFS; Pao et al., 1998). These transporters are integral membrane proteins, with 12-14 predicted transmembrane domains, that mediate the import of siderophores in a highly regulated process (Philpott, 2006).

Several homeostatic mechanisms that ensure the maintenance of copper at a sufficient concentration for cell growth have been identified. Copper homeostasis in fungi is maintained by the transcriptional regulation of genes involved in copper acquisition, mobilization and sequestration and also at the posttranslational level (Gross et al., 2000). In S. cerevisiae copper is reduced from $\mathrm{Cu}$ (II) to $\mathrm{Cu}$ (I) by cell surface metalloreductases (Hassett and Kosman,
1995; Georgatsou et al., 1997) and uptake is mediated by Ctrlp and Ctr3p, two high-affinity transporters. Both $c t r 1$ and $c t r 3$ genes are regulated at the transcriptional level in response to copper availability, being induced by copper deprivation (Dancis et al., 1994a; Pena et al., 2000). The vacuolar copper transporter Ctr2p is also involved in the intracellular copper homeostasis, since it provides copper via mobilization of intracellular copper stores (Rees et al., 2004).

Zinc homeostasis is maintained by posttranslational and transcriptional homeostatic regulatory mechanisms (Lyons et al., 2000; Eide, 2003). Unlike iron and copper, zinc is taken up as divalent cation. Once inside the cell, zinc is neither oxidized nor reduced (Berg and Shi, 1996). In S. cerevisiae the uptake of zinc is mediated by two separate systems. One system has a high-affinity for this metal and is active in zinc-limited conditions (Zhao and Eide, 1996a). The second system has a lower affinity for zinc and is not highly regulated by zinc concentrations (Zhao and Eide, 1996b). The expression of the high-affinity zinc transporter Zrtlp and the low-affinity zinc transporter Zrt2p is regulated by the transcription factor Zap1p, which plays a central role in zinc homeostasis (Zhao and Eide, 1997). The zinc transporter activity is also posttranslationally regulated. High levels of extracellular zinc trigger the inactivation of $\mathrm{Zrtl} \mathrm{p}$ through endocytosis of the protein and its subsequent degradation in the vacuole (Gitan et al., 1998).

This paper focuses on the metabolism of iron, copper and zinc in the fungal pathogens Paracoccidioides brasiliensis, Cryptococcus neoformans var. grubii, and Cryptococcus gattii. Low iron conditions have been associated with the susceptibility of $P$. brasiliensis, the etiological agent of paracoccidioidomycosis (PCM), to the antimicrobial action of monocytes (Dias-Melicio et al., 2005). Major phenotypic changes in C. neoformans, the etiological agent of cryptococcosis, are regulated by iron availability. For example, low iron concentrations result in the induction of capsule enlargement and the repression of laccase (Jung and Kronstad, 2008). Although iron regulation is well described in Cryptococcus species (Jung et al., 2008), iron associated processes are poorly understood in $P$. brasiliensis. Further, there is limited information on the impact of copper and zinc in P. brasiliensis, as well as the impact of zinc in Cryptococcus species. In this paper we performed in silico analyses of genes related to iron, copper and zinc metabolism in P. brasiliensis, C. neoformans var. grubii and C. gattii. We also compared the obtained information with data available from S. cerevisiae, which represents the most deeply studied model fungus, and other fungi.

\section{MATERIALS AND METHODS}

Sequences of genes related to iron, copper and zinc uptake, as well as to siderophore biosynthesis and uptake were used in the search of orthologs of P. brasiliensis and Cryptococcus species genomes. The P. brasiliensis database ${ }^{1}$ includes the genomes of three isolates ( $P b 01$, $\mathrm{Pb03}$, and $\mathrm{Pb} 18$ ) and the cryptococcal database includes genomes of C. neoformans var. grubii ${ }^{2}$ and C. gattii ${ }^{3}$. The sequences used in

${ }^{1}$ http://www.broadinstitute.org/annotation/genome/paracoccidioides_brasiliensis/ MultiHome.html

${ }^{2} \mathrm{http}$ //www.broadinstitute.org/annotation/genome/cryptococcus_neoformans/ MultiHome.html

${ }^{3}$ http://www.broadinstitute.org/annotation/genome/cryptococcus_neoformans_b/ MultiHome.html 
the in silico analysis were obtained from the NCBI databank ${ }^{4}$, and they are primarily from $S$. cerevisiae, but also include genes from other fungi, such as Aspergillus fumigatus, Aspergillus nidulans, C. albicans and $H$. capsulatum. The search by orthologs was based on sequence similarity by using the BLAST tool. The expectation value adopted in the databases search was $E$-value $\leq 10^{-5}$.

The deduced amino acid sequences of the orthologs found in P. brasiliensis isolates and Cryptococcus species were analyzed. Searches for conserved domains and signal peptides in the orthologs proteins were performed using the Conserved Domain Database at $\mathrm{NCBI}^{5}$ and the online software SMART ${ }^{6}$. Predictions of putative transmembrane segments were made using the TopPred ${ }^{7}$ server and SMART software. Amino acid sequences alignment were performed using the ClustalX2 (Larkin et al., 2007).

\section{RESULTS AND DISCUSSION}

\section{IRON}

\section{Uptake of iron at the cell surface by the reductive system}

To better understand how $P$. brasiliensis could acquire iron by the reductive system, in silico analyses were performed utilizing

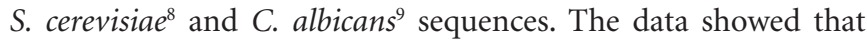
Pb01 contains four metalloreductase (Frep) homologs, $P b 03$ five homologs, and $\mathrm{Pb} 18$ three homologs (Table 1). The genes encoding metalloreductases were fre 1, fre3, fre 5, fre 7 and frp1. Also, $P b 01$ and $P b 03$ have two homologs each of the ferroxidase Fetp and $P b 18$ has one. The reductive uptake system was first described in S. cerevisiae (Lesuisse et al., 1987). The enzymatic reduction step in S. cerevisiae is catalyzed by members of the FRE family of metalloreductases. The products of the fre genes are not specific for iron reduction, since they can also promote copper reduction. S. cerevisiae Fre1p and Fre $2 \mathrm{p}$ are required for growth on media with low concentrations of ferric iron salts. Fre $3 p$ and Fre $4 p$ catalyze uptake of iron from siderophores and Fre7p is under the control of the copperdependent transcription factor Maclp (Philpott and Protchenko, 2008). The expression of $C$. albicans ferric reductase Frplp is upregulated by alkaline $\mathrm{pH}$ and iron-limited conditions (Liang et al., 2009). Future studies are required to dissect the roles of the different $P$. brasiliensis reductases, especially in in vivo conditions.

Homologs for iron permeases (Ftrp and Fthp) were not found in $P$. brasiliensis genomes, corroborating the hypothesis that iron is transported by the zinc permeases, as previously suggested by transcriptional analyses (Bailão et al., 2006, 2007; Costa et al., 2007). However, in the present in silico analysis, we identified five zinc transporters (Table 1). These permeases could be coupled with one or more of the ferroxidases homologs (Fet5p, Fet31p and Fet33p) identified in the $P$. brasiliensis genome database. In S. cerevisiae, reduced iron is taken up through a high-affinity transport complex that consists of Fet3p, a multi-copper ferroxidase, and Ftr1p, a permease. Independent studies have demonstrated that Fet3p produced by $S$. cerevisiae $\Delta f t r 1$ mutant cells is retained in a cytoplasmic

${ }^{4}$ http://www.ncbi.nlm.nih.gov/guide/

${ }^{5}$ http://www.ncbi.nlm.nih.gov/Structure/cdd/wrpsb.cgi

${ }^{6} \mathrm{http}: / /$ smart.embl-heidelberg.de/

${ }^{7}$ http://mobyle.pasteur.fr/cgi-bin/portal.py?form=toppred

${ }^{8}$ http://www.yeastgenome.org/

${ }^{9}$ http://www.candidagenome.org/ compartment in a copper-free, inactive form. Correspondingly, Ftrlp produced by $S$. cerevisiae $\Delta f e t 3$ mutant cells fails to reach the plasma membrane (Stearman et al., 1996). These observations are in agreement with a model in which the two proteins form a heterodimer or higher order structure for correct maturation and trafficking to the plasma membrane (Kosman, 2003).

The $P$. brasiliensis genomes analysis revealed the presence of a $g g t 1$ homolog. This gene is presumably responsible for the glutathione (GSH)-dependent iron reduction activity previously identified in functional studies (Zarnowski and Woods, 2005). The proposed mechanism comprises secretion of a glutathione-dependent ferric reductase (GSH-FeR), named Ggtlp, that purportedly utilizes siderophores and $\mathrm{Fe}^{3+}$-binding proteins as substrates, enhancing the enzymatic activity under iron-limiting conditions, which is consistent with the function of a high-affinity uptake system, as described in H. capsulatum (Timmerman and Woods, 2001).

Homologs of permease genes involved in low-affinity iron reductive systems, such as smf, were not detected in our analysis. Hence, the low-affinity permease utilized by $P$. brasiliensis to acquire iron could be one of the zinc permeases, as suggested (Table 1). Despite the absence of iron permease $f t h 1$ gene homologs, $P$. brasiliensis has one $c c c 1$ gene homolog that could drive iron vacuolar transport. P. brasiliensis also has homologs of the mitochondrial iron transporters genes $m r s 3$ and $m r s 4$ and the mitochondrial iron chaperone Yfhlp, suggesting mitochondrial iron homeostasis in this pathogen (Table 1). Since mitochondria are major users of iron, it follows that they should contain machinery required for its transport. Mrs3p and Mrs4p are homologous and functionally redundant proteins found in the inner mitochondrial membrane of $S$. cerevisiae, which are involved in transport under iron-limiting conditions (Foury and Roganti, 2002). Yfh1p, a homolog of human frataxin, is also involved in mitochondrial iron homeostasis (Babcock et al., 1997). While Mrs3p and Mrs4p mediate iron delivery from the outside to the inside of mitochondria, the frataxin homolog facilitates the use of iron within this organelle, functioning as a mitochondrial matrix iron chaperone (Zhang et al., 2006; Froschauer et al., 2009).

Cryptococcal genomic databases analysis revealed both S. cerevisiae and C. albicans homologs for proteins related to iron metabolism (Table 1). Remarkably, the C. neoformans var. grubii database contains four metalloreductase homologs, while the $C$. gattii genome has three similar homologs. The reason for the multiplicity of metalloreductases isoenzymes is not clear, although it is speculated that some sets of genes are expressed under specific conditions for iron acquisition (Kornitzer, 2009). Concerning the ferroxidases, C. neoformans var. grubii has three homologs and C. gatti contains one. Both genomes possess two iron permeases homologs, whose presence is supported by prior functional analyses (Jung et al., 2008). Two iron permeases, gene orthologs of S. cerevisiae ftr 1 , have been identified in C. neoformans, namely Cft1p and Cft2p (Jung et al., 2008). The expression of the $c f t 1$ gene is down-regulated at high iron concentrations, suggesting that its product functions as a high-affinity iron permease. The role of $c f t 2$ is still unclear, although it supposedly encodes a low-affinity iron permease or a vacuolar permease that could transport stored iron to the cytoplasm, similar to what occurs in S. cerevisiae with the iron permease Fth1p. One of the iron permeases here identified is probably a Fthlp homolog, which 
Table 1 | Orthologs to genes related to iron, copper and zinc uptake by reductive systems in $P$. brasiliensis and Cryptococcus species.

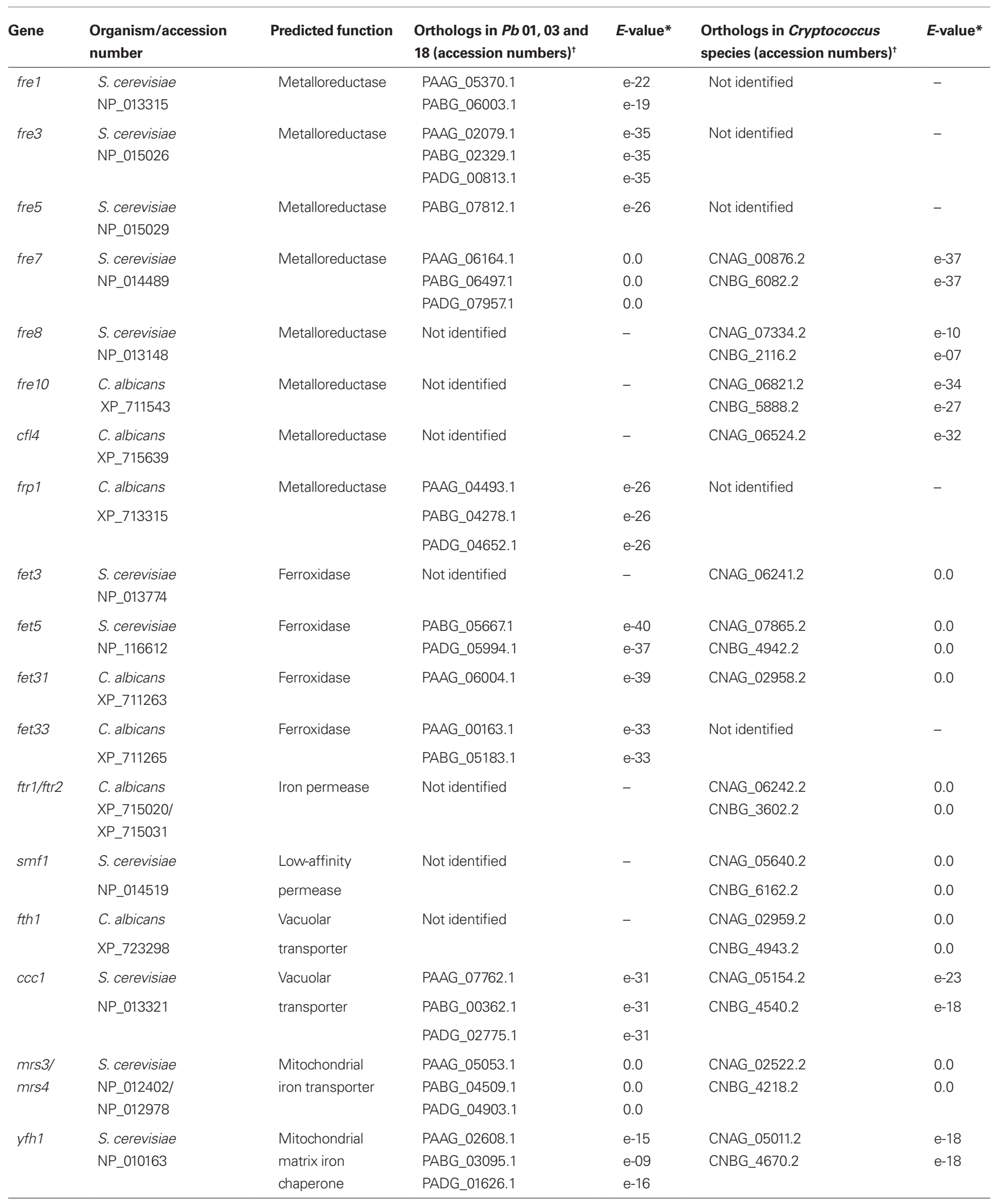


Table 1 | Continued

\begin{tabular}{|c|c|c|c|c|c|c|}
\hline ggt1 & $\begin{array}{l}\text { H. capsulatum } \\
\text { EGC49121 }\end{array}$ & $\begin{array}{l}\text { Secreted } \\
\text { glutathione- } \\
\text { dependent ferric } \\
\text { reductase }\end{array}$ & $\begin{array}{l}\text { PAAG_06130.1 } \\
\text { PABG_06527.1 } \\
\text { PADG_07986.1 }\end{array}$ & $\begin{array}{l}0.0 \\
0.0 \\
0.0\end{array}$ & $\begin{array}{l}\text { CNAG_02888.2 } \\
\text { CNBG_3537.2 }\end{array}$ & $\begin{array}{l}0.0 \\
0.0\end{array}$ \\
\hline ctr3 & $\begin{array}{l}\text { S. cerevisiae } \\
\text { NP_013515 }\end{array}$ & $\begin{array}{l}\text { High-affinity } \\
\text { copper } \\
\text { transporter of } \\
\text { the plasma } \\
\text { membrane }\end{array}$ & $\begin{array}{l}\text { PAAG_05251.1 } \\
\text { PABG_07607.1 } \\
\text { PADG_05084.1 }\end{array}$ & $\begin{array}{l}e-22 \\
e-21 \\
e-21\end{array}$ & $\begin{array}{l}\text { CNAG_00979.2 } \\
\text { CNBG_0560.2 }\end{array}$ & $\begin{array}{l}e-14 \\
e-14\end{array}$ \\
\hline ctr2 & $\begin{array}{l}\text { S. cerevisiae } \\
\text { NP_012045 }\end{array}$ & $\begin{array}{l}\text { Putative } \\
\text { low-affinity } \\
\text { copper } \\
\text { transporter of } \\
\text { the vacuolar } \\
\text { membrane }\end{array}$ & $\begin{array}{l}\text { PABG_01536.1 } \\
\text { PADG_04146.1 }\end{array}$ & $\begin{array}{l}e-14 \\
e-14\end{array}$ & CNAG_01872.2 & $e-13$ \\
\hline cup2 & $\begin{array}{l}\text { S. cerevisiae } \\
\text { NP_011922 }\end{array}$ & Metallothionein & Not identified & - & Not identified & - \\
\hline sod1 & $\begin{array}{l}\text { S. cerevisiae } \\
\text { NP_012638 }\end{array}$ & $\begin{array}{l}\text { Cytosolic } \\
\text { superoxide } \\
\text { dismutase }\end{array}$ & $\begin{array}{l}\text { PAAG_04164.1 } \\
\text { PABG_03954.1 } \\
\text { PADG_07418.1 }\end{array}$ & $\begin{array}{l}0.0 \\
0.0 \\
0.0\end{array}$ & $\begin{array}{l}\text { CNAG_01019.2 } \\
\text { CNBG_0599.2 }\end{array}$ & $\begin{array}{l}0.0 \\
0.0\end{array}$ \\
\hline sod2 & $\begin{array}{l}\text { S. cerevisiae } \\
\text { NP_011872 }\end{array}$ & $\begin{array}{l}\text { Mitochondrial } \\
\text { superoxide } \\
\text { dismutase }\end{array}$ & $\begin{array}{l}\text { PAAG_02725.1 } \\
\text { PABG_03204.1 } \\
\text { PADG_01755.1 }\end{array}$ & $\begin{array}{l}0.0 \\
0.0 \\
0.0\end{array}$ & $\begin{array}{l}\text { CNAG_04388.2 } \\
\text { CNBG_2661.2 }\end{array}$ & $\begin{array}{l}0.0 \\
0.0\end{array}$ \\
\hline$z r t 1$ & $\begin{array}{l}\text { S. cerevisiae } \\
\text { NP_011259 }\end{array}$ & $\begin{array}{l}\text { High-affinity zinc } \\
\text { transporter of } \\
\text { the plasma } \\
\text { membrane }\end{array}$ & $\begin{array}{l}\text { PAAG_08727.1 } \\
\text { PABG_07725.1 } \\
\text { PADG_08567.1 }\end{array}$ & $\begin{array}{l}0.0 \\
0.0\end{array}$ & $\begin{array}{l}\text { CNAG_03398.2 } \\
\text { CNBG_2209.2 }\end{array}$ & $\begin{array}{l}e-40 \\
e-41\end{array}$ \\
\hline$z r t 2$ & $\begin{array}{l}\text { S. cerevisiae } \\
\text { NP_013231 }\end{array}$ & $\begin{array}{l}\text { Low-affinity zinc } \\
\text { transporter of } \\
\text { the plasma } \\
\text { membrane }\end{array}$ & $\begin{array}{l}\text { PAAG_03419.1 } \\
\text { PABG_05498.1 } \\
\text { PADG_06417.1 }\end{array}$ & $\begin{array}{l}e-27 \\
e-26 \\
e-28\end{array}$ & CNAG_00895.2 & 0.0 \\
\hline
\end{tabular}


Table 1 | Continued

\begin{tabular}{|c|c|c|c|c|c|c|}
\hline$z r c 1$ & $\begin{array}{l}\text { S. cerevisiae } \\
\text { NP_013970 }\end{array}$ & $\begin{array}{l}\text { Vacuolar } \\
\text { membrane zinc } \\
\text { transporter }\end{array}$ & PAAG_00702.1 & $e-41$ & Not identified & - \\
\hline $\cot 1$ & $\begin{array}{l}\text { S. cerevisiae } \\
\text { NP_014961 }\end{array}$ & $\begin{array}{l}\text { Vacuolar } \\
\text { membrane zinc } \\
\text { transporter }\end{array}$ & $\begin{array}{l}\text { PAAG_07885.1 } \\
\text { PABG_07467.1 } \\
\text { PADG_08196.1 }\end{array}$ & $\begin{array}{l}e-44 \\
0.0 \\
0.0\end{array}$ & $\begin{array}{l}\text { CNAG_02806.2 } \\
\text { CNBG_3460.2 }\end{array}$ & $\begin{array}{l}e-40 \\
e-37\end{array}$ \\
\hline$z r t 3$ & $\begin{array}{l}\text { S. cerevisiae } \\
\text { NP_012746 }\end{array}$ & $\begin{array}{l}\text { Vacuolar } \\
\text { membrane zinc } \\
\text { transporter }\end{array}$ & $\begin{array}{l}\text { PAAG_09074.1 } \\
\text { PABG_04697.1 } \\
\text { PADG_05322.1 }\end{array}$ & $\begin{array}{l}e-23 \\
e-22 \\
e-23\end{array}$ & Not identified & - \\
\hline$m s c 2$ & $\begin{array}{l}\text { S. cerevisiae } \\
\text { NP_010491 }\end{array}$ & $\begin{array}{l}\text { Cation diffusion } \\
\text { facilitator protein } \\
\text { of the } \\
\text { endoplasmic } \\
\text { reticulum and } \\
\text { nucleus }\end{array}$ & $\begin{array}{l}\text { PABG_07115.1 } \\
\text { PADG_06381.1 }\end{array}$ & $\begin{array}{l}e-40 \\
e-40\end{array}$ & $\begin{array}{l}\text { CNAG_05394.2 } \\
\text { CNBG_4458.2 }\end{array}$ & $\begin{array}{l}e-23 \\
e-24\end{array}$ \\
\hline zap1 & $\begin{array}{l}\text { S. cerevisiae } \\
\text { NP_012479 }\end{array}$ & $\begin{array}{l}\text { Zinc-regulated } \\
\text { transcription } \\
\text { factor }\end{array}$ & $\begin{array}{l}\text { PAAG_03645.1 } \\
\text { PABG_03305.1 } \\
\text { PADG_01870.1 }\end{array}$ & $\begin{array}{l}e-20 \\
e-18 \\
e-24\end{array}$ & $\begin{array}{l}\text { CNAG_05392.2 } \\
\text { CNBG_4460.2 }\end{array}$ & $\begin{array}{l}e-40 \\
e-28\end{array}$ \\
\hline
\end{tabular}

${ }^{*}$ Similarities with E-values $<10^{-5}$ were considered significant.

${ }^{\dagger}$ Accession numbers: PAAG refers to Pb01; PABG refers to Pb03; PADG refers to Pb18; CNAG refers to C. neoformans var. grubii and CNBG refers to C. gattii.

is likely involved in vacuolar iron uptake. Moreover, we could identify iron transporter $c c c 1$ gene homologs in the genome, suggesting that a vacuolar iron homeostasis system exists in Cryptococcus. Data mining revealed one homolog of the low-affinity gene smf family, confirming the presence of both high and low-affinity iron reductase systems, as described (Jacobson et al., 1998). The presence of mitochondrial $m r s 3, m r s 4$ and $y f h 1$ gene homologs in C. neoformans var. grubii supports a mechanism for iron homeostasis (Nyhus and Jacobson, 1999; Jacobson et al., 2005). Additionally, our in silico analyses demonstrated that cryptococcal reductive systems are closely related to that of $S$. cerevisiae (Table 1 ). Although no activity for the enzyme glutathione-dependent ferric reductase had been reported in Cryptococcus, both genomes contain ggt1 homologs suggesting the presence of a GSH-FeR system. A comparative analysis of iron uptake by reductive systems in $P$. brasiliensis, C. neoformans var. grubii and C. gattii is depicted in Figure 1.

\section{Conserved domains in proteins related to the reductive iron metabolism}

Amino acid sequence analyses of orthologs proteins found in the $P$. brasiliensis isolates and Cryptococcus species may support the assumption of conserved functions. Searching for conserved domains in all the analyzed sequences (Table A1 in Appendix) revealed that most of the $P$. brasiliensis and Cryptococcus deduced proteins codified by the genes related to reductive iron metabolism contain conserved domains related to specific functions. Regarding to metalloreductases, the presence of a ferric reductase domain and a FAD - and/or a NAD-binding domain can be essential for functional enzymatic activity, since they are responsible for electron donation, as described in other organisms (De Luca and Wood, 2000). A sche- matic diagram presenting the cited motifs in a metalloreductase Frep is shown in Figure 2. An HPFTXXS motif is believed to be a site for FAD-binding and a glycine-rich motif and a cysteine-glycine couple are thought to be involved in NADPH binding (Shatwell et al., 1996). As well, copper-oxidase domains are required for ferroxidase activity. S. cerevisiae Fet3p is a multi-copper-oxidase and, like other copper proteins, possesses three distinct types of $\mathrm{Cu}^{2+}$-binding sites. Oxidation of $\mathrm{Fe}^{2+}$ occurs at the type 1 copper site followed by the reduction of molecular oxygen to $2 \mathrm{H}_{2} \mathrm{O}$ at the other two copper sites (Hassett et al., 1998; Kosman, 2003). The ferroxidases in the $P$. brasiliensis isolates and Cryptococcus species present such domain, suggesting they are functional proteins.

\section{Siderophore production}

Culture supernatants of $P$. brasiliensis grown in media with low iron concentrations display higher iron binding capacity when compared with culture supernatants from iron-rich media (Arango and Restrepo, 1988), which has suggested that siderophores are involved in iron acquisition in this fungus. Furthermore, in silico analysis of $P$. brasiliensis structural genomes indicates that this fungus can potentially produce siderophores. The three sequenced $P$. brasiliensis genomes show sequences that potentially encode all the necessary enzymes for siderophore synthesis: sidA, sidF, sidC and sidD (A. fumigatus orthologs), as shown in Table 2 and Figure 1. This biosynthetic pathway may lead to the production of hydroxamate-type siderophores. The first committed step in siderophore biosynthesis is the $\mathrm{N}^{5}$-hydroxylation of ornithine catalyzed by ornithine- $\mathrm{N}^{5}$-oxygenase. The sid1 gene of Ustilago maydis, the etiologic agent of corn smut, was the first characterized fungal ornithine- $\mathrm{N}^{5}$-oxygenase-encoding gene (Mei et al., 1993). 


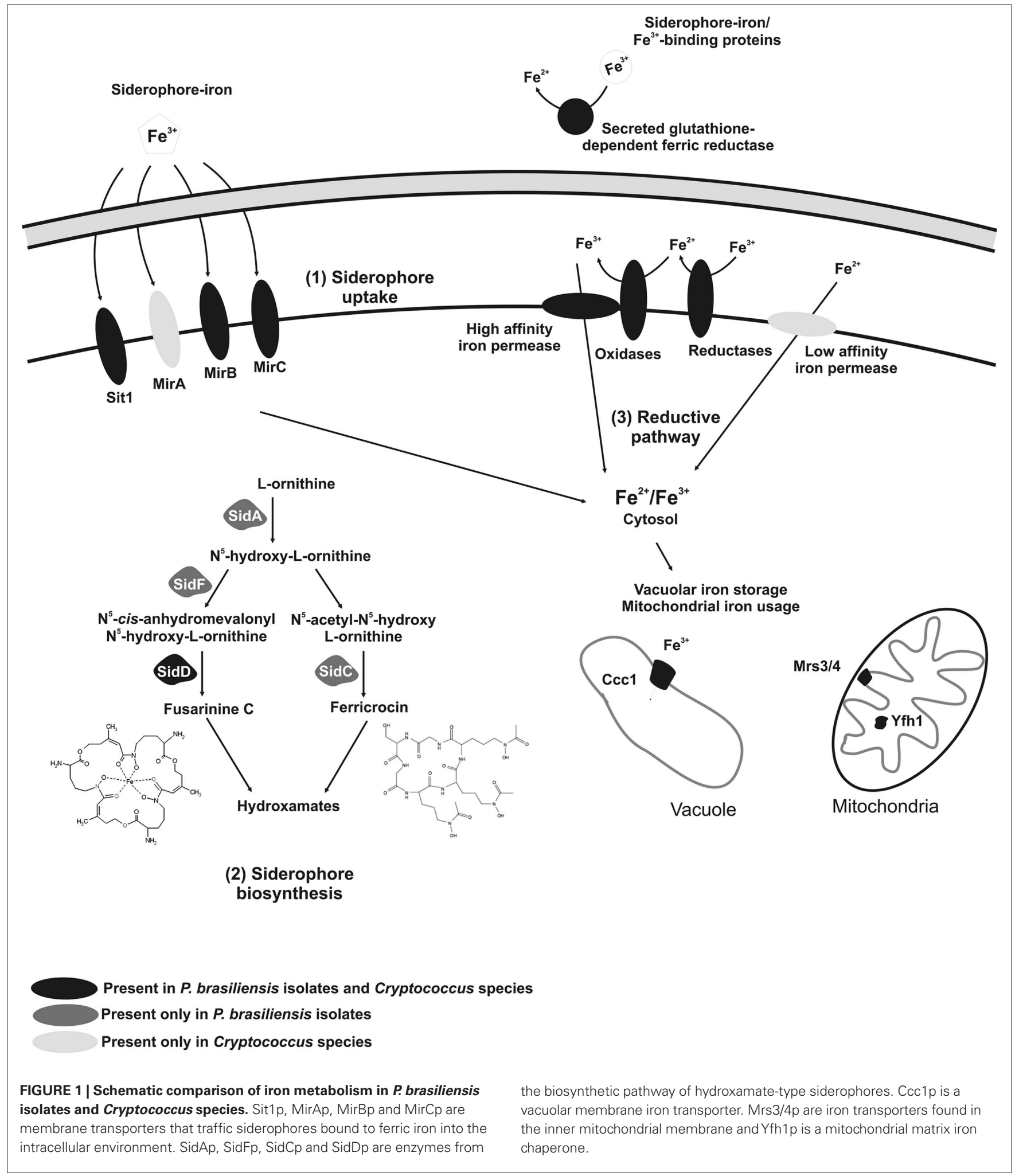

Orthologs of sid1 have been identified in A. fumigatus (sidA) and H. capsulatum (sid1). In the latter, disruption of sid1 causes poor growth under low iron conditions and loss of siderophore production, suggesting an important role of siderophore production in iron-limiting conditions (Schrettl et al., 2004; Hwang et al., 2008). The formation of the hydroxamate group consists of the transfer of an acyl group from acyl-coenzyme A to $N^{5}$-hydroxyornithine. Different acyl group usage results in the production of distinct 


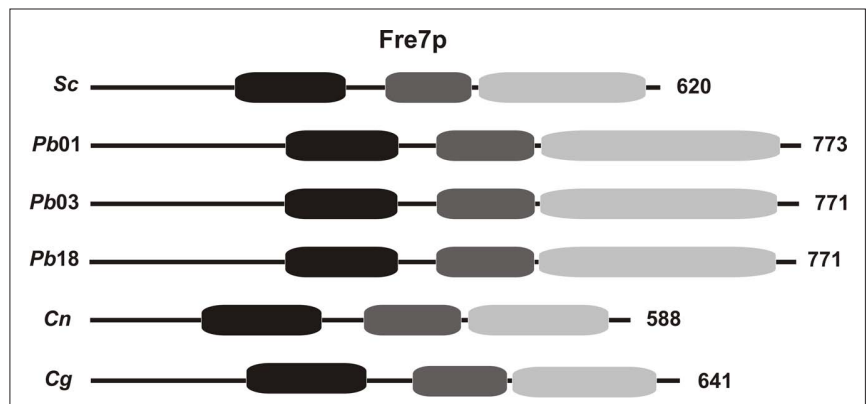

FIGURE 2 | Domains found in a Frep related to iron reductive uptake in $\boldsymbol{P}$ brasiliensis isolates and Cryptococcus species. The found domains are: ferric reductase domain (black boxes), FAD-binding domain (dark gray boxes) and NAD-binding domain (light gray boxes). The length of each protein, in amino acids, is shown on the right. Accession numbers: Sc (NP_014489), Pb01 (PAAG_06164.1), Pb03 (PABG_06497.1), Pb18 (PADG_07957.1), Cn (CNAG_00876.2) and Cg (CNBG_6082.2).

siderophores. Acetyl is used for rhodotorulic acid and ferrichrome synthesis, while anhydromevalonyl is utilized in the fusarinines and coprogens pathway (Haas et al., 2008). A. fumigatus sidF encodes an $N^{5}$-hydroxyornithine:cis anhydromevalonyl coenzyme A- $\mathrm{N}^{5}$-transacylase involved in the synthesis of fusarinine and triacetylfusarinine (Schrettl et al., 2007). The sidF ortholog of $H$. capsulatum, sid3 gene, is transcriptionally induced under iron restricted conditions (Hwang et al., 2008). Hydroxamates are covalently linked via peptide (rhodotorulic acid, ferrichromes, coprogens) or ester bonds (fusarinines, coprogens) carried out by non-ribosomal peptide synthetases (NRPSs; Finking and Marahiel, 2004). In A. fumigatus, sidC and sidD encode two NRPSs involved in ferricrocin (intracellular siderophore) and triacetylfusarinine C (TAFC) biosynthesis, respectively. Some siderophores additionally require acetylation at the $\mathrm{N}^{2}$-amino group, such as coprogen and TAFC. For example, sidG deletion in A. fumigatus results in the abrogation of the TAFC siderophore production (Schrettl et al., 2007). Given that our in silico analysis of $P$. brasiliensis identified sequences capable of coding for SidAp, SidFp, SidCp and SidDp, it is reasonable to hypothesize that $P$. brasiliensis may be able to synthesize both extracellular and intracellular siderophores.

Although Cryptococcus species have been described as unable to produce siderophores (Jacobson and Petro, 1987), in silico analysis of C. neoformans var. grubii and C. gattii structural genomes indicates the presence of sidD and sidG genes, which are also involved in other metabolic pathways in fungi. However, sidA and sidF genes were not found, and these genes are essential, especially since they act early in the pathway for siderophores production (Table 2; Figure 1). It will be interesting to examine if sidA and sidF have other functions and how siderophore-associated iron uptake was replaced to account for this loss.

\section{Conserved domains in proteins related to siderophore biosynthesis}

As described above, the third siderophore biosynthetic step is performed by NRPSs. These enzymes have a modular structure where one module, the catalytic unit, is composed of an adenylation domain (A) for substrate specificity and activation, a peptidyl carrier (PCP) domain that binds a 4'phosphopantetheine cofactor for attachment of the activated substrate, and a condensation (C) domain for bond formation (Finking and Marahiel, 2004). As Cryptococcus species are not siderophore producers, NRPSs domains analysis was performed only with SidCp ortholog found in P. brasiliensis genomes. These analyses revealed that, as in A. fumigatus, the three domains essential for NRPS function are present in SidCp from the three P. brasiliensis isolates examined (Figure 3A). Domains found in other siderophore biosynthesis related proteins are shown in Table A2 in Appendix.

\section{Siderophore uptake}

The presence of orthologs for appropriate siderophore genes and the fact that the iron binding capacity of medium from low iron cultures of $P$. brasiliensis is greater than that of iron-replete medium (Arango and Restrepo, 1988) supports our hypothesis that P. brasiliensis produces and captures siderophores from the extracellular environment. Therefore, we have categorized putative P. brasiliensis siderophore transporters by sequence homology analysis (Table 2; Figure 1). Searches of the $P$. brasiliensis genomes revealed that all three isolates contain the S. cerevisiae gene homolog SIT sit1. S. cerevisiae can utilize siderophore-bound iron either by the reductive iron-assimilation system or by membrane transporters. In the latter case, the uptake is mediated by four transporters that differ in substrate specificity: Sit1p/Arn3p, Arn1p, Taf1p/Arn2p, Enb1p/Arn4p (Lesuisse et al., 1998; Heymann et al., 1999, 2000; Yun et al., 2000a,b). Sit1p/Arn3p recognizes ferrioxamines, coprogen, and ferrichromes lacking anhydromevalonic acid. Additionally, P. brasiliensis isolates possess the A. nidulans SIT gene homologs, mirB, and mirC (Table 2; Figure 1). Heterologs expression assays of $A$. nidulans mir genes in a $S$. cerevisiae mutant strain unable to uptake siderophores have demonstrated that MirBp transports native TAFC, a hydroxamate siderophore. The growth of $P$. brasiliensis is stimulated by coprogen $B$ and dimerum acid (DA), a derivative of rhodotorulic acid from Blastomyces dermatitidis, suggesting that $P$. brasiliensis can use hydroxamate compounds as iron sources (Castaneda et al., 1988).

The siderophore transporter Sit1p/Arn3p and the transporters of the SIT-family ( $m i r A$, mirB and mirC) were found in C. neoformans var. grubii and C. gattii (Table 2; Figure 1). The homolog gene sit1/arn 3 was previously identified in C. neoformans var. neoformans using SAGE employed to examine the transcriptome under ironlimiting and iron-replete conditions (Lian et al., 2005). Mutants defective in sit 1 had increased melanin production and elevated transcript levels for the laccase gene, lac1. The melanin phenotype may be caused by changes in iron homeostasis or membrane trafficking, perhaps leading to altered copper loading of laccase in the cell wall. Studies with mutants lacking sit1/arn3 in C. neoformans var. grubii and C. neoformans var. neoformans have demonstrated that the gene sit1 is required for siderophore utilization (ferrioxamine B) and growth in low iron-environments (Tangen et al., 2007). An overview of the siderophore biosynthesis and uptake in P. brasiliensis and Cryptococcus species is shown in Figure 1.

Analysis of transmembrane domains in siderophore-iron transporters Amino acid sequences of siderophore transporter orthologs found in P. brasiliensis isolates and Cryptococcus species were analyzed in the TopPred server to predict their transmembrane domain topologies. Figure 3B presents the transmembrane segments of Sit1p in S. cerevisiae, P. brasiliensis isolates, C. neoformans var. grubii and C. gattii. 
Table 2 | Orthologs to genes related to siderophore biosynthesis and to iron uptake by the non-reductive siderophore transport system in P. brasiliensis and Cryptococcus species.

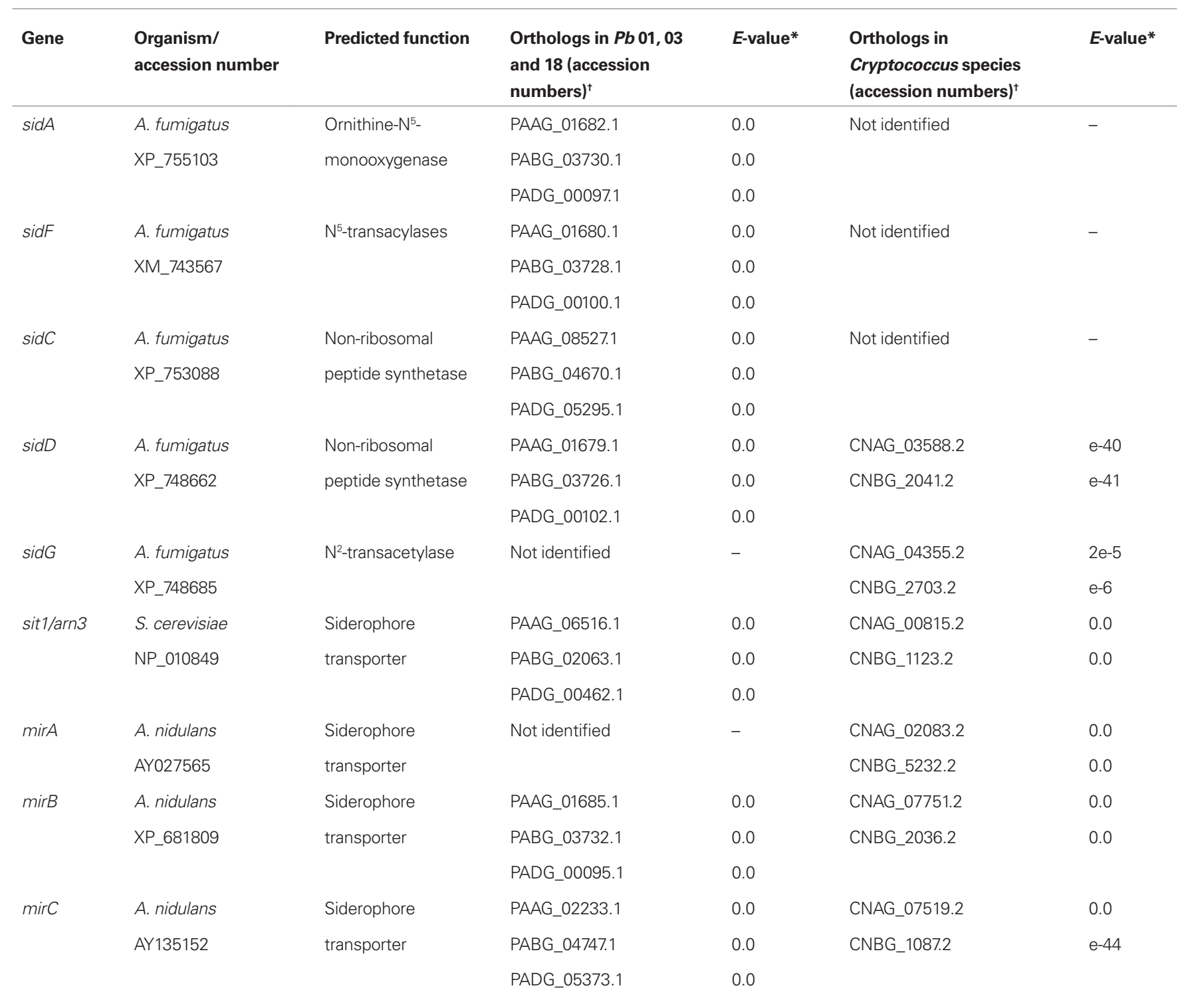

* Similarities with E-values $<10^{-5}$ were considered significant.

${ }^{\dagger}$ Accession numbers: PAAG refers to Pb01; PABG refers to Pb03; PADG refers to Pb18; CNAG refers to C. neoformans var. grubii and CNBG refers to C. gattii.

The number of segments varies between 12 and 15 . Identical topology was found in Sitlp from P. brasiliensis isolates $P b 03$ and $P b 18$, whereas $P b 01$ has a different topology. Transmembrane domains were also identified in all the other siderophore transporters, as shown in Table A2 in Appendix. These transporters also contain a MFS1 domain, which indicates that they belong to the MFS of transporters.

\section{Iron source preferences}

Several fungal pathogens utilize heme or hemoglobin as sources of iron (Foster, 2002; Jung et al., 2008). C. albicans expresses surface receptors for hemoglobin and hemolytic factors (Manns et al., 1994). Interestingly, heme-iron utilization in C. albicans is facilitated by Rbt5p, an extracellular glycosylphophatidylinositol (GPI)-anchored hemoglobin-binding protein (Weissman et al., 2008). Although there is no experimental evidence regarding the utilization of iron from the heme group by P. brasiliensis, there are genes that show similarity with Hmx-1p (Pendrak et al., 2004), and exhibit a heme oxygenase domain (PAAG_06626.1 in Pb01; PABG_02644.1 in Pb03; PADG_01082.1 in Pb18) in each of the P. brasiliensis isolates. These genes are annotated as conserved hypothetical or as predicted proteins. C. neoformans var. grubii is also able to utilize heme and hemoglobin as iron sources, but the mechanism(s) of heme utilization by this fungus are still unclear (Jung et al., 2008).

Transferrin has also been shown to be an iron source for both C. albicans and C. neoformans var. grubii. These fungi employ highaffinity permeases to acquire iron from transferrin in mammalian 

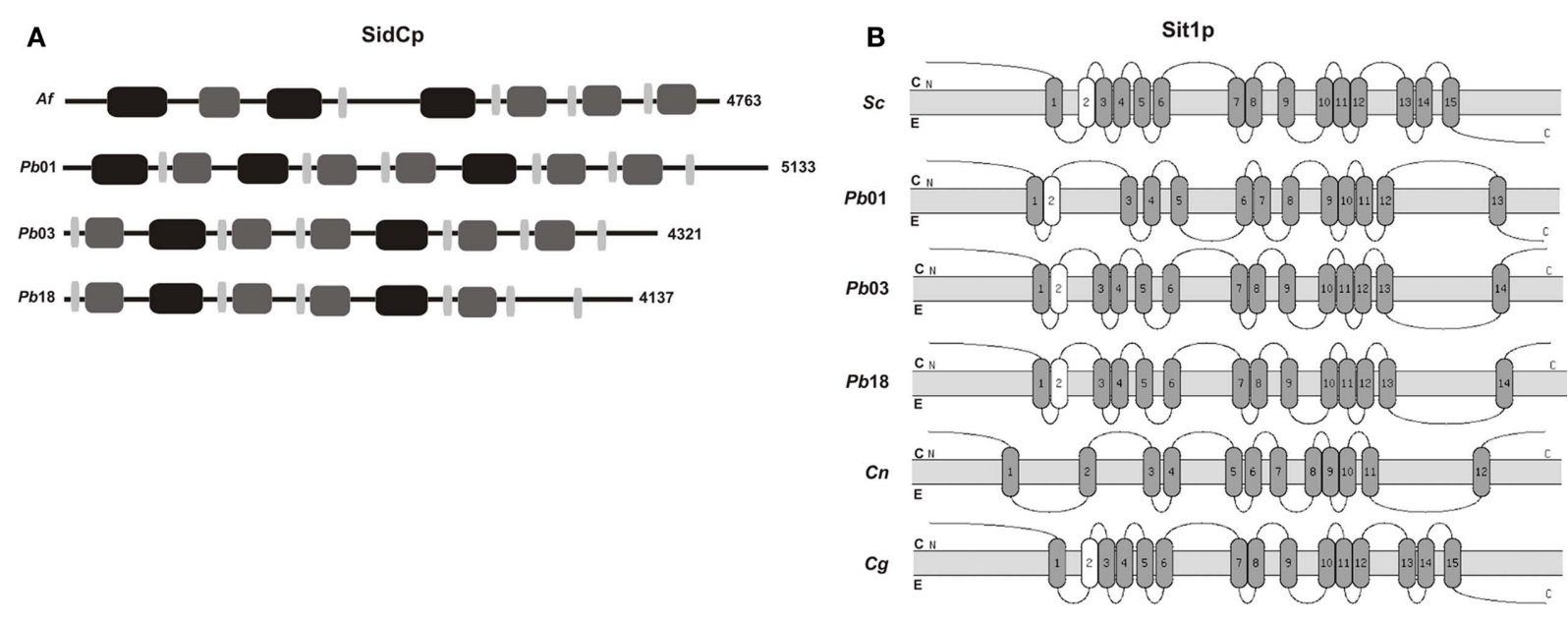

FIGURE 3 | Conserved features in proteins involved in biosynthesis and uptake of siderophores. (A) Modular organization of SidCp in P. brasiliensis isolates. Black boxes represent adenylation (A) domain, dark gray boxes illustrate the condensation $(C)$ domain and light gray boxes represent the peptidyl carrier (PCP) domain. The length of each protein, in amino acids, is shown on the right. (B) Topology of transmembrane domains of Sit1p from S. cerevisiae, P. brasiliensis isolates and Cryptococcus species. White boxes represent putative segments, according to cutoff parameters (cutoff for certain transmembrane segments 1.00; cutoff for putative transmembrane segments 0.60). E: extracellular environment; C: cytosol. The topology prediction was performed using the TopPred server. Accession numbers in A: Af (XP_753088), Pb01 (PAAG_08527.1), Pb03 (PABG_04670.1), Pb18 (PADG_05295.1). Accession numbers in B: Sc (NP_010849), Pb01 (PAAG_06516.1), Pb03 (PABG_02063.1), Pb18 (PADG_00462.1), Cn (CNAG_00815.2), and Cg (CNBG_1123.2). hosts through the reductive system (Knight et al., 2005; Jung et al., 2008). In the $P$. brasiliensis genome databases, genes were found (PAAG_04670.1; PABG_00038.1; PADG02428.1, respectively for isolates $\mathrm{Pb} 01, \mathrm{~Pb} 03$ and $\mathrm{Pb} 18$ ) with high similarity to $\mathrm{Cft} 1 \mathrm{p}$, a permease from $C$. neoformans var. grubii required for iron utilization from transferrin (Jung et al., 2008).

\section{COPPER}

\section{Copper uptake by the reductive system}

Little is known about copper metabolism in P. brasiliensis. However, our in silico analyses of the $S$. cerevisiae copper metabolism-related genes in comparison to $P$. brasiliensis genomic databases revealed genes related to the copper reduction metalloreductase, fre. Copper transport is well described in S. cerevisiae where it is reduced from $\mathrm{Cu}$ (II) to $\mathrm{Cu}$ (I) by several cell surface metalloreductases encoded by several fre genes. These metalloreductases are regulated by iron and copper availability, mediated by the transcriptional factor Maclp (Jungmann et al., 1993). Homologs of the copper metalloregulatory transcription factor gene $(m a c 1)$ are present in both $P b 01$ and $\mathrm{Pb} 03$ genomes, but not in $\mathrm{Pb} 18$. Additionally, the high-affinity copper transport (Ctr3p) was found in all three isolate genomes. In $S$. cerevisiae, after reduction, copper is transported by the highaffinity copper transporter comprised by Ctr3p and Ctr1p, which are functionally redundant, although they have distinct amino acid sequences. Ctr3p is an integral membrane protein that assembles as a trimer to form a competent copper uptake permease at the plasma membrane. S. cerevisiae Ctrlp is localized at the plasma membrane and exists as an oligomer in vivo. These two high-affinity copper transport proteins are induced by copper deprivation and repressed by copper excess (Dancis et al., 1994a; Pena et al., 2000). In our in silico analyses, genes for the high-affinity copper transporter of the plasma membrane (ctr1) were not found, suggesting that highaffinity copper transport is performed only by the Ctr3p protein.
Genes related to metallochaperone (atx 1$), \mathrm{Cu}^{2+}$ transporting P-type ATPase $(c c c 2)$ and superoxide dismutases ( $\operatorname{sod} 1$ and $\operatorname{sod} 2$; Table 1) were also found in P. brasiliensis genomes. In the cell, copper is transported by Atxlp, a cytosolic copper metallochaperone protein, that transports $\mathrm{Cu}(\mathrm{I})$ to $\mathrm{Ccc} 2 \mathrm{p}$, a transporting P-type ATPase containing a cytoplasmic region containing two distinct soluble metal-binding domains that interact with Atxlp (Banci et al., 2007). Ccc2p mediates the export of copper from the cytosol and distributes it to cupric proteins (Yuan et al., 1997). S. cerevisiae also has a detoxification pathway formed by Cup1p and Cup2p, metallothioneins (Table 1), that protect against copper poisoning (Hamer et al., 1985). An alternative copper transport system is mediated by Ctr2p, a vacuolar membrane protein of S. cerevisiae, that mobilizes vacuolar copper stores to cytosolic copper chaperones (Rees et al., 2004). Homologs of the low-affinity copper transporter of the vacuolar membrane (Ctr2p) are in $\mathrm{Pb} 03$ and $\mathrm{Pb} 18$, but not in $\mathrm{Pb} 01$. Additionally, the metallothioneins (encoded by cup1 and cup2 genes) were not identified in $P$. brasiliensis isolates $P b 01, P b 03$ and $P b 18$.

In silico analysis (Table 1) revealed that Cryptococcus species have orthologs encoding ferric/cupric reductases, suggesting that the copper reduction process is similar to that described for S. cerevisiae. Homologs of the high-affinity copper transporter $c t r 3$ gene and copper metalloregulatory transcription factor gene ( $m a c 1$ ) have previously been identified (Waterman et al., 2007). Also, proteins with similarity to the cytosolic copper metallochaperone (atx1 gene), the $\mathrm{Cu}^{2+}$ transporting P-type ATPase ( $\operatorname{ccc} 2$ gene) and the cytosolic and mitochondrial superoxide dismutases ( $\operatorname{sod} 1$ and $\operatorname{sod} 2$ genes) have also identified, suggesting that copper distribution in Cryptococcus species occurs as described in S. cerevisiae. A homolog of the ctr2 gene was identified only in C. neoformans var. grubii. Recently it was demonstrated that Ctr2p links copper homeostasis to polysaccharide capsule production in C. neoformans. The lack of this protein resulted in increased phagocytosis by murine macro- 
phage, sensitivity to copper starvation and defects in polysaccharide capsule formation and melanization (Chun and Madhani, 2010). The gene $\operatorname{ctr} 1$ for the high-affinity copper transporter of the plasma membrane and the genes cup 1 and cup 2 for metallothioneins were not found in Cryptococcus species. These analyses suggest that the high-affinity copper transport in cryptococcal cells is primarily performed by the protein encoded by $c t r 3$.

\section{Analysis of conserved motifs present in copper transporters}

Searches for conserved domains revealed the presence of Mets and MXXXM motifs in the Ctr3p of the P. brasiliensis isolates and the Cryptococcus species (Figure 4). Studies in yeast and mammalian cells have revealed that proteins of the CTR family are integral membrane proteins containing three membrane-spanning domains, with high protein sequence homology (Dancis et al., 1994a; Lee et al., 2002). With the exception of $S$. cerevisiae Ctr3p, all CTR family members are rich in methionine residues within the amino-terminal portion (Labbe et al., 1999). These residues are arranged as MXXM and/or MXM, called Mets motifs, and it has been suggested that they could be involved in extracellular copper binding (Dancis et al., 1994b). It has been demonstrated that these clustered methionine residues together with an MXXXM motif in the transmembrane domain of CTR family members are important for copper uptake (Puig et al., 2002). In P. brasiliensis the MXXXM motif is found within the third transmembrane segment. The Ctr3p of Cryptococcus species contains only two predicted transmembrane domains instead of the three transmembrane segments described for other fungi. In C. neoformans var. grubii and C. gattii, the MXXXM motif is within the second transmembrane domain. Conserved domains were also found in amino acid sequences of other proteins involved in copper metabolism (Table A1 in Appendix), suggesting that the orthologs found in P. brasiliensis and Cryptococcus may have activities that are similar to genes with established functions in other fungi.

\section{ZINC}

\section{Zinc uptake}

Comparisons to the $S$. cerevisiae genes related to zinc metabolism performed in P. brasiliensis genomes are presented in Table 1. Analyses demonstrate that $P$. brasiliensis has homologs to zinc trans- porters described in S. cerevisiae that are localized in the plasmatic, vacuolar and endoplasmic reticulum membranes. Importantly, five genes encoding to transporters of the ZIP family, with homology to $S$. cerevisiae Zrt1p or Zrt2p, are in the P. brasiliensis genomic database. In $S$. cerevisiae, zinc is transported by proteins belonging to the ZIP family, which is composed by a zinc high-affinity transporter protein encoded by the zrtl gene and a low-affinity transporter encoded by the zrt2 gene (Gaither and Eide, 2001). We have previously identified homologs of zinc transporters by transcriptional analysis of $P$. brasiliensis yeast cells after incubation in human blood and plasma (Bailão et al., 2006, 2007). Interestingly, $P$. brasiliensis isolate $P b 01$ has two vacuolar membrane zinc transporters, encoded by the $z r c 1$ and $\cot 1$ genes, whereas isolates $P b 03$ and $\mathrm{Pb} 18$ contain only the cot 1 homolog. Intracellularly, zinc is in vacuoles in association with the vacuolar membrane proteins $\mathrm{Zrclp}$ and Cot1p, members of the cation diffusion facilitator (CDF) family (MacDiarmid et al., 2002). A homolog of the transcription factor Zap1p is also present in the three P. brasiliensis isolates. The expression of the genes associated with zinc homeostasis is positively regulated in S. cerevisiae by the transcription factor Zap1p, which regulates the expression of $z r t 1, z r t 2, z r t 3$, fet 4 , and $z c r 1$ under zinc limiting conditions (Wu et al., 2008). Therefore, zinc assimilation in P. brasiliensis may be similar to that of S. cerevisiae.

Similarly, zinc homeostasis in Cryptococcus species is poorly studied. In silico analysis was performed by comparing $S$. cerevisiae genes related to zinc metabolism in genomic cryptococcal databases (Table 1). The results show that C. neoformans var. grubii and C. gattii have Zrt1p and Zrt2p zinc transporters homologs. These proteins putatively internalize zinc into the cell. Further, homologs of the vacuolar transporter Cot $1 \mathrm{p}$ and the CDF Msc2p are present. Cot1p is presumably in the vacuolar membrane and should be related to zinc storage in this compartment. Msc2p, an endoplasmic reticulum membrane zinc transporter, could be related to zinc transport to this organelle. The protein encoded by $m s c 2$ (CDF) is responsible for zinc homeostasis in the endoplasmic reticulum in S. cerevisiae (Ellis et al., 2004). A homolog of the transcription factor Zaplp is also present in Cryptococcus. Since homologs to the vacuolar membrane zinc transporter gene $z r t 3$ were not identified, the $z r c 1$ and cot1 genes, encoding vacuolar membrane zinc transporters

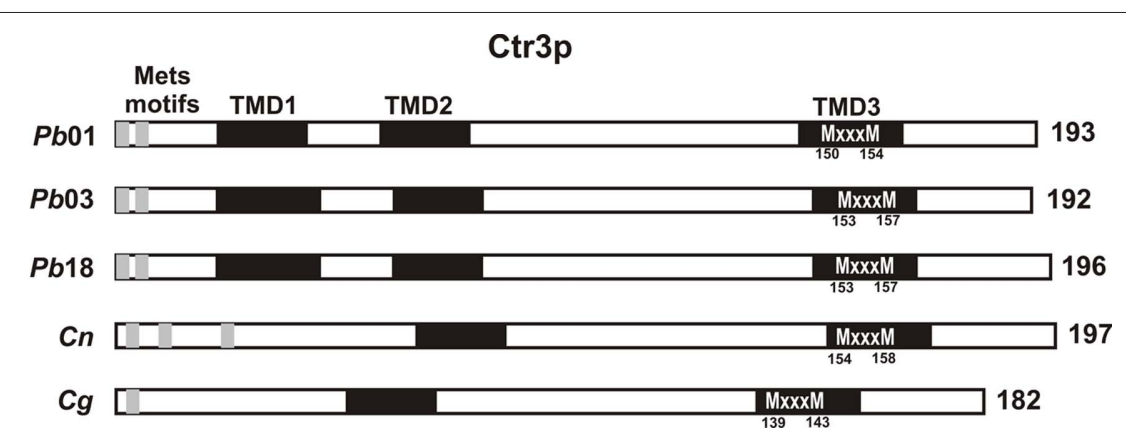

FIGURE 4 | Conserved features found in the primary structure of Ctr3p of P. brasiliensis isolates and Cryptococcus species. Ctr $3 p$ from P. brasiliensis isolates contains three putative transmembrane domains (TMD1-3, shown in black) while Ctr3p from Cryptococcus species presents only two TMDs. All species contain putative copper binding motifs (Mets motifs) arranged as
MXXM and/or MXM. MXXXM motif in TMD3 in P. brasiliensis isolates and TMD2 in Cryptococcus species are represented in white characters. The length of each protein, in amino acids, is shown on the right. Accession numbers: $P b 01$ (PAAG_05251.1), Pb03 (PABG_07607.1), Pb18 (PADG_05084.1), Cn (CNAG_00979.2) and Cg (CNBG_0560.2). 


\section{Zrt1p}

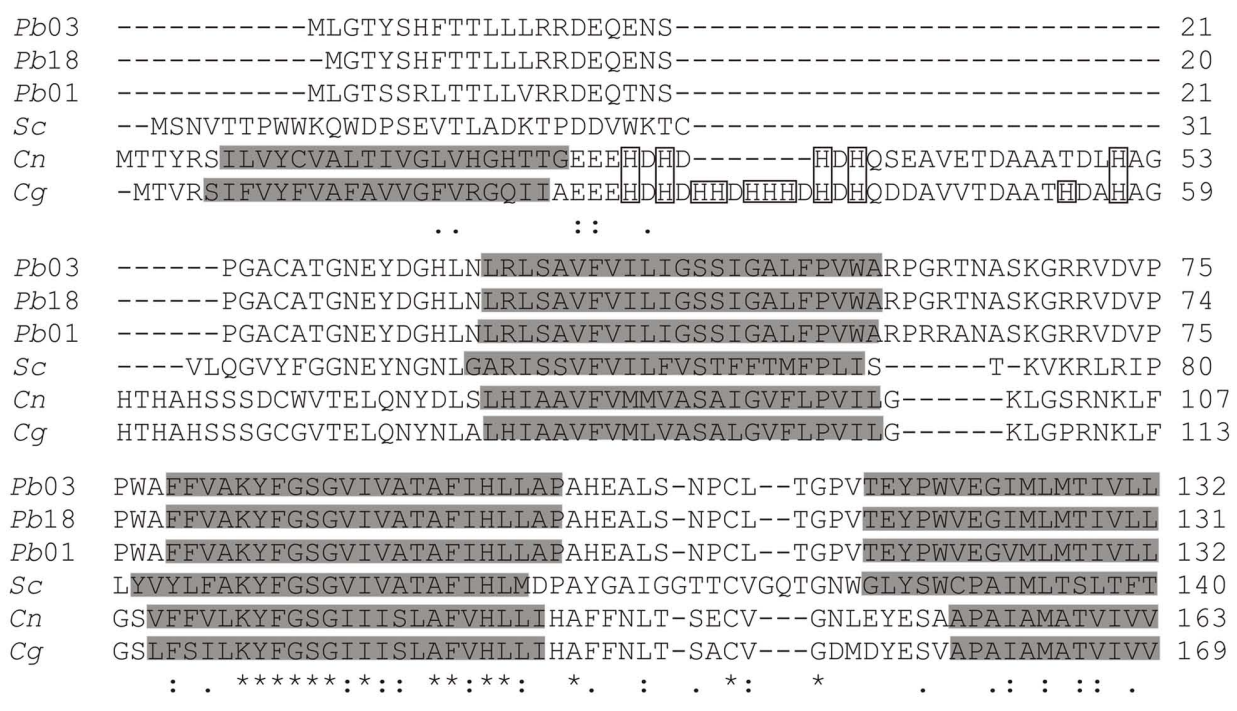

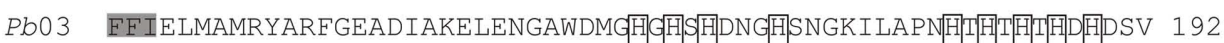
Pb18 FFIELMAMRYARFGEADIAKELENGAWDMGHGH SHDIHGH SNGKILAPNHTHTHTHDHDSV 191 PbO1 EFIELMAMRYARFGEADIAKELENGAWDLGHGHSHDHGH SNGKILAPTHTHNHNDHDSV 192 SC ELTDLESS--------VWVER------KYGLSHDHTHDEIKDTVVRNTAAVSSENDNE 184 Cn WLVDFLGSR------------------YITRQNSYVPECDRNISAALCSSSEPLGERK 203 Cg WLVDFEGSR-----------------YIARQNSCLPEGDRNITAASSSYPVSQGEKK 209 $:::::$

$$
\therefore \quad \text { : } \quad: \quad:
$$

Pb03 NSDVNTNIPGEDHLGHARHHLTDAVSKKNCHSFVGKTAADSKNHGPSDHTHGHMSLVEDY 252 Pb18 NSDVNTNFPGENHLGHARHHLTDAVSKKNCHISFVGKTAADSKNHGPPDHTHGHMS LVEDY 251 PbO1 NSDVNTHMPGEDHLGHVRHHTTDAVSKKNCHSLVGKTAADSKNHSPPDRPHGHMALVEDY 252 SC NGTANGSHDTKN--GVEYYEDSDATS------------------------MDVVQSF 215 Cn KDDISTPMTELACCGPKNLEITNFDG-----------------------------AA 231

Cg IDGISTPMTELACCGPNKSKVTPFDG-------------------------AA 237

Pb03 SAQLTSIFILEFGIIFHSVEIGLTLAVAGKEFITLYIVLVFHQTFEGLGLGARIATVPWP 312 Pb18 SAQLTSIFILEFGIIFHSVFIGLTLAVAGKEFITLYIVLVFHQTEEGLGLGARIATVPWP 311 Pb01 SAQLTSIFILEFGIIHHSVEIGLTLAVAGKEFITLYIVLVEHQTEEGLGLGARIATVPWP 312 SC QAQEYAFLILEFGVIFHSVMIGINLGSVGDEFSSLYPVLVFHQSFEGLGIGARLSAIEFP 275 Cn KTAHWNVQLLEYGVIFHSIMIGVSLGAMGTGFNTTFAALVFHQLEEGLGLGARIAMLIWP 291 Cg KTAHWNVQLLEYGVIFHSIMIGVSLGAMGTGFNTTFAALVEHQLFEGLGLGARIAMLVWP 297

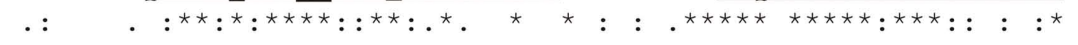

Pb03 G--SKRLTPYILAIAFGLSTPVAIAIGLGVHETYPPESOTSLIVNGVEDSISAGILIYTA 370

Pb18 G--SKRLTPYILAIAFGLSTPVAIAIGLGVHETYPPESQTSLIVNGVFDSISAGILIYTA 369

Pb01 G--SKRLTPYILAIAFGLSTPIAIAIGLGIHETYPPESQTSLIVNGVFDSISAGILIYTA 370

SC R--SKRWWPWALCVAYGLTTPICVAIGLGVRTRYVSGSYTALVISGVLDAISAGILLYTG 333

Cn AGISSAIKKWWMCLAYALATPVGIAIGIGVHESVNMNGRAILLSTGILDSISAGILLYCG 351

Cg PGVSSTIKKWAMCLAYALVTPVGIAIGIGVHES INMNGRAILLSTGILDSISAGILLYGG 357

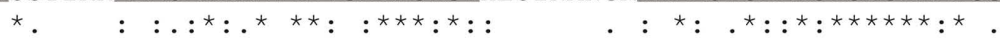

Pb03 LVELMAHEFMFSTTMRRAS IRTVLAAFALLCLGAALMALLGKWA 414

Pb18 LVELMAHEFMFSTTMRRAS IRTVLAAFALLCLGAALMALIGKWA 413

Pb01 LVELMAHEFMFSTTMRRASIRTVLAAFALLCLGAALMALLGKWA 414

SC LVELLARDFIFNP-QRTKDLRELSFNVICTLFGAGIMALIGKWA 376

Cn LCQLLYREWVVGE-MRDASTSKIIVALVSLFLGLFAMSFIGKWI 394

Cg LCQLLYREWVVGD-MRDASTGEIIVALVSLFLGLFAMSEIGKWI 400

* : ${ }^{\star}:::: . \quad * \quad . \quad: \quad$ : ${ }^{\star}{ }^{\star}::: * \star \star$

FIGURE 5 | Alignment of amino acid sequences of Zrt1p from S. cerevisiae, $P$. brasiliensis isolates and Cryptococcus species. The predicted transmembrane domains are shown in gray boxes. The black boxes inside the transmembrane segment contain conserved histidine-serine and glycine residues. The histidines found in the amino-terminal region of Zrt1p from
Cryptococcus species and in the loop between transmembrane domains III and IV in P. brasiliensis and S. cerevisiae are boxed. Asterisks indicate amino acid identity and dots represent conserved substitutions. Accession numbers: Pb03 (PABG_07725.1), Pb18 (PADG_08567.1), Pb01 (PAAG_08727.1), Sc (NP_011259), Cn (CNAG_03398.2) and Cg (CNBG_2209.2). 
could be responsible for the zinc transport to this organelle. This analysis suggests that $C$. neoformans var. grubii and $C$. gattii could obtain zinc via routes similar to that described for S. cerevisiae.

\section{Analysis of conserved regions in the high-affinity zinc transporter (Zrt1p) in P. brasiliensis isolates and Cryptococcus species}

Alignment of Zrtlp amino acid sequence from S. cerevisiae, P. brasiliensis isolates and Cryptococcus species revealed some conserved features (Figure 5). Concerning the predicted transmembrane domain number, all $P$. brasiliensis isolates contain eight predicted domains, while both C. neoformans var. grubii and C. gattii have nine. Proteins belonging to the ZIP family are predicted to have from five to eight transmembrane domains and they vary in size from 233 to 477 amino acid residues. The variations in the aminoterminal portion are usually responsible for the differences in size. The transmembrane domain IV has the most conserved portions of ZIP family proteins, with conserved histidine and glycine residues. The histidine residue and the adjacent polar residue, usually a serine, within the transmembrane domain are predicted to comprise part of a heavy metal-binding site in the center of the membrane (Eng et al., 1998). The amino acid sequence of $S$. cerevisiae Zrtlp presents a number of histidine residues in a large loop between the transmembrane segments III and IV, which is a putative metal ion binding site (Zhao and Eide, 1996a). The histidine-serine and glycine residues are conserved within the fourth transmembrane region in $P$. brasiliensis and within the fifth transmembrane region in Cryptococcus. Regarding the histi-

\section{REFERENCES}

Arango, R., and Restrepo, A. (1988). Growth and production of iron chelants by Paracoccidioides brasiliensis mycelial and yeast forms. J. Med. Vet. Mycol. 26, 113-118.

Babcock, M., de Silva, D., Oaks, R., Davis-Kaplan, S., Jiralerspong, S., Montermini, L., Pandolfo, M., and Kaplan, J. (1997). Regulation of mitochondrial iron accumulation by Yfhlp, a putative homolog of frataxin. Science 276, 1709-1712.

Bailão, A. M., Schrank, A., Borges, C. L., Dutra, V., Molinari-Madlum, E. E. W. I., Felipe, M. S. S., Mendes-Giannini, M. J.S., Martins, W. S., Pereira, M., and Soares, C. M. A. (2006). Differential gene expression by Paracoccidioides brasiliensis in host interaction conditions: representational difference analysis identifies candidate genes associated with fungal pathogenesis. Microbes Infect. 8, 2686-2697.

Bailão, A. M., Shrank, A., Borges, C. L., Parente, J. A., Dutra, V., Felipe, M. S., Fiuza, R. B., Pereira, M., and Soares, C. M.A. (2007). The transcriptional profile of Paracoccidioides brasiliensis yeast cells is influenced by human plasma. FEMS Immunol. Med. Microbiol. 51, 43-57.

Banci, L., Bertini, I., Chasapis, C. T., Rosato, A., and Tenori, L. (2007).
Interaction of the two soluble metalbinding domains of yeast Ccc2 with copper(I)-Atx1.Biochem. Biophys. Res. Commun. 364, 645-649.

Berg, J. M., and Shi, Y. (1996). The galvanization of biology: a growing appreciation for the roles of zinc. Science 271, 1081-1085.

Castaneda,E., Brummer,E.,Perlman,A.M., McEwen,J.G., and Stevens, D.A. (1988). A culture medium for Paracoccidioides brasiliensis with high plating efficiency, and the effect of siderophores. J. Med. Vet. Mycol. 26, 351-358.

Chun, C. D., and Madhani, H. D. (2010). Ctr2 links copper homeostasis to polysaccharide capsule formation and phagocytosis inhibition in the human fungal pathogen Cryptococcus neoformans. PLoS ONE 5, e12503. doi: 10.1371/journal.pone.0012503

Costa, M., Borges, C. L., Bailao, A. M., Meirelles, G. V., Mendonca, Y. A., Dantas, S. F., de Faria, F. P., Felipe, M. S., Molinari-Madlum, E. E., Mendes-Giannini, M. J., Fiuza, R. B., Martins, W.S., Pereira, M., and Soares, C.M. (2007). Transcriptome profiling of Paracoccidioides brasiliensis yeastphase cells recovered from infected mice brings new insights into fungal response upon host interaction. Microbiology 153, 4194-4207. dine rich region, it is conserved between transmembrane domains III and IV in P. brasiliensis isolates, whereas are conserved at the amino-terminal portion in Cryptococcus species, as occurs in other members of the ZIP family (Eng et al., 1998). Conserved domains are also found in amino acid sequences of other proteins involved in zinc metabolism that were identified in the search for orthologs (Table A1 in Appendix).

\section{CONCLUSION}

As we have described, microorganisms are extremely well equipped to exploit host metal sources during growth and infection. Cryptococcus species demonstrate remarkable flexibility in gaining access to and utilizing iron, the most investigated micronutrient in this organism. Our laboratories have begun to elucidate the mechanisms for the uptake and metabolism of micronutrients such as iron, copper and zinc in $P$. brasiliensis. Studies on individual genes and pathways are revealing unique features of micronutrients metabolism in this fungus. The application of systems biology approaches that incorporates genomic and proteomic data will further generate hypotheses about the common and specific responses to micronutrient deprivation in both pathogenic fungi and potentially lead to the development of novel therapeutics exploiting their metal requirements.

\section{ACKNOWLEDGMENT}

This work at laboratories was supported by grants from MCT/ FINEP/Rede GENOPROT Grant number 01.07.0552.00.
Dancis, A., Haile, D., Yuan, D. S. and Klausner, R. D. (1994a). The Saccharomyces cerevisiae copper transport protein (Ctrlp). Biochemical characterization, regulation by copper, and physiologic role in copper uptake. J. Biol. Chem. 269, 25660-25667.

Dancis, A., Yuan, D. S., Haile, D., Askwith, C., Eide, D., Moehle, C., Kaplan, J., and Klausner, R. D. (1994b). Molecular characterization of a copper transport protein in S. cerevisiae: an unexpected role for copper in iron transport. Cell 76, 393-402.

De Luca, N. G., and Wood, P. M. (2000). Iron uptake by fungi: contrasted mechanisms with internal or external reduction. Adv. Microb. Physiol. 43, 39-74.

Dias-Melicio, L. A., Calvi, S. A., Peracoli, M. T., and Soares, A. M. (2005) Inhibitory effect of deferoxamine on Paracoccidioides brasiliensis survival in human monocytes: reversal by holotransferrin not by apotransferrin. Rev. Inst. Med. Trop. Sao Paulo 47, 263-266.

Eide, D. J. (2003). Multiple regulatory mechanisms maintain zinc homeostasis in Saccharomyces cerevisiae. J. Nutr. 133, 1532S-1535S.

Ellis, C. D., Wang, F., MacDiarmid, C. W., Clark, S., Lyons, T., and Eide, D.
J. (2004). Zinc and the Msc2 zinc transporter protein are required for endoplasmic reticulum function. $J$. Cell Biol. 166, 325-335.

Eng, B. H., Guerinot, M. L., Eide, D., and Saier, M. H. Jr. (1998). Sequence analyses and phylogenetic characterization of the ZIP family of metal ion transport proteins. J. Membr. Biol. 166, 1-7. Finking, R., and Marahiel, M. A. (2004). Biosynthesis of nonribosomal peptides. Annu. Rev. Microbiol. 58, 453-488.

Foster, L. A. (2002). Utilization and cell-surface binding of hemin by Histoplasma capsulatum. Can. J. Microbiol. 48, 437-442.

Foury, F., and Roganti, T. (2002). Deletion of the mitochondrial carrier genes MRS3 and MRS4 suppresses mitochondrial iron accumulation in a yeast frataxin-deficient strain. J. Biol. Chem. 277, 24475-24483.

Froschauer, E. M., Schweyen, R. J., and Wiesenberger, G. (2009). The yeast mitochondrial carrier proteins Mrs3p/ Mrs4 $\mathrm{p}$ mediate iron transport across the inner mitochondrial membrane. Biochim. Biophys. Acta 1788, 1044-1050.

Gaither, L. A., and Eide, D. J. (2001). Eukaryotic zinc transporters and their regulation. Biometals 14, 251-270. 
Georgatsou, E., Mavrogiannis, L. A., Fragiadakis, G. S., and Alexandraki, D. (1997). The yeast Frelp/Fre2p cupric reductases facilitate copper uptake and are regulated by the coppermodulated Maclp activator. J. Biol. Chem. 272, 13786-13792.

Gitan, R.S., Luo, H., Rodgers, J., Broderius, M., and Eide, D. (1998).Zinc-induced inactivation of the yeast ZRT1 zinc transporter occurs through endocytosis and vacuolar degradation. J. Biol. Chem. 273, 28617-28624.

Gross, C., Kelleher, M., Iyer, V. R., Brown, P. O., and Winge, D. R. (2000). Identification of the copper regulon in Saccharomyces cerevisiae by DNA microarrays. J. Biol. Chem. 275, 32310-32316.

Haas, H., Eisendle, M., and Turgeon, B. G. (2008). Siderophores in fungal physiology and virulence. Annu. Rev. Phytopathol. 46, 149-187.

Hamer, D. H., Thiele, D. J., and Lemontt, J.E. (1985). Function and autoregulation of yeast copperthionein. Science 228, 685-690.

Hassett, R., and Kosman, D. J. (1995). Evidence for $\mathrm{Cu}(\mathrm{II})$ reduction as a component of copper uptake by Saccharomyces cerevisiae. J. Biol. Chem. 270, 128-134.

Hassett, R. F., Yuan, D. S., and Kosman, D. J. (1998). Spectral and kinetic properties of the Fet 3 protein from Saccharomyces cerevisiae, a multinuclear copper ferroxidase enzyme. J. Biol. Chem. 273, 23274-23282.

Heymann, P., Ernst, J. F., and Winkelmann, G. (1999). Identification of a fungal triacetylfusarinine $\mathrm{C}$ siderophore transport gene (TAF1) in Saccharomyces cerevisiae as a member of the major facilitator superfamily. Biometals 12, 301-306.

Heymann, P., Ernst, J.F., and Winkelmann, G. (2000). A gene of the major facilitator superfamily encodes a transporter for enterobactin (Enblp) in Saccharomyces cerevisiae. Biometals 13, 65-72.

Howard, D. H. (1999). Acquisition, transport, and storage of iron by pathogenic fungi. Clin. Microbiol. Rev. 12, 394-404.

Hwang, L. H., Mayfield, J. A., Rine, J., and Sil, A. (2008). Histoplasma requires SID1, a member of an iron-regulated siderophore gene cluster, for host colonization. PLoS Pathog. 4, e1000044. doi: 10.1371/journal.ppat.1000044

Jacobson, E. S., Goodner,A. P., and Nyhus, K. J. (1998). Ferrous iron uptake in Cryptococcus neoformans. Infect. Immun. 66, 4169-4175.

Jacobson, E. S., and Petro, M. J. (1987). Extracellular iron chelation in Cryptococcus neoformans. J. Med. Vet. Mycol. 25, 415-418.
Jacobson, E. S., Troy, A. J., and Nyhus, K. J. (2005). Mitochondrial functioning of constitutive iron uptake mutations in Cryptococcus neoformans. Mycopathologia 159, 1-6.

Jung, W. H., and Kronstad, J. W. (2008). Iron and fungal pathogenesis: a case study with Cryptococcus neoformans. Cell. Microbiol. 10, 277-284.

Jung, W. H., Sham, A., Lian, T., Singh, A., Kosman, D. J., and Kronstad, J. W. (2008). Iron source preference and regulation of iron uptake in Cryptococcus neoformans. PLoS Pathog. 4, e45. doi: 10.1371/journal.ppat.0040045

Jungmann, J., Reins, H. A., Lee, J., Romeo, A., Hassett, R., Kosman, D., and Jentsch, S. (1993). MAC1, a nuclear regulatory protein related to $\mathrm{Cu}$-dependent transcription factors is involved in $\mathrm{Cu} / \mathrm{Fe}$ utilization and stress resistance in yeast. $E M B O J .12$, 5051-5056.

Kim, B. E., Nevitt, T., and Thiele, D. J. (2008). Mechanisms for copper acquisition, distribution and regulation. Nat. Chem. Biol. 4, 176-185.

Knight, S. A., Vilaire, G., Lesuisse, E., and Dancis, A. (2005). Iron acquisition from transferrin by Candida albicans depends on the reductive pathway. Infect. Immun. 73, 5482-5492.

Kornitzer, D. (2009). Fungal mechanisms for host iron acquisition. Curr. Opin. Microbiol. 12, 377-383.

Kosman, D. J. (2003). Molecular mechanisms of iron uptake in fungi. Mol. Microbiol. 47, 1185-1197.

Labbe, S., Pena, M. M., Fernandes, A. R., and Thiele, D. J. (1999). A copper-sensing transcription factor regulates iron uptake genes in Schizosaccharomyces pombe. J. Biol. Chem. 274, 36252-36260.

Larkin, M. A., Blackshields, G., Brown, N. P., Chenna, R., McGettigan, P. A., McWilliam, H., Valentin, F., Wallace, I. M., Wilm, A., Lopez, R., Thompson, J. D., Gibson, T. J., and Higgins, D. G. (2007). Clustal W and Clustal X version 2.0. Bioinformatics 23, 2947-2948.

Lee, J., Pena, M. M., Nose, Y., and Thiele, D. J. (2002). Biochemical characterization of the human copper transporter Ctr1. J. Biol. Chem. 277, 4380-4387.

Lesuisse, E., Raguzzi, F., and Crichton, R. R. (1987). Iron uptake by the yeast Saccharomyces cerevisiae: involvement of a reduction step. J. Gen. Microbiol. 133, 3229-3236.

Lesuisse, E., Simon-Casteras, M., and Labbe, P. (1998). Siderophoremediated iron uptake in Saccharomyces cerevisiae: the SIT1 gene encodes a ferrioxamine $\mathrm{B}$ permease that belongs to the major facilitator superfamily. Microbiology 144(Pt 12), 3455-3462.

Lian, T., Simmer, M. I., D’Souza, C. A., Steen, B. R., Zuyderduyn, S. D., Jones,
S. J., Marra, M. A., and Kronstad, J. W. (2005). Iron-regulated transcription and capsule formation in the fungal pathogen Cryptococcus neoformans. Mol. Microbiol. 55, 1452-1472.

Liang, Y., Gui, L., Wei, D. S., Zheng, W., Xing, L. J., and Li, M. C. (2009) Candida albicans ferric reductase FRP1 is regulated by direct interaction with Rim101p transcription factor. FEMS Yeast Res. 9, 270-277.

Lyons, T. J., Gasch, A. P., Gaither, L. A., Botstein, D., Brown, P. O., and Eide, D. J. (2000). Genome-wide characterization of the Zaplp zinc-responsive regulon in yeast. Proc. Natl. Acad. Sci. U.S.A. 97, 7957-7962.

MacDiarmid, C. W., Milanick, M. A., and Eide, D. J. (2002). Biochemical properties of vacuolar zinc transport systems of Saccharomyces cerevisiae.J. Biol. Chem. 277, 39187-39194.

Manns, J. M., Mosser, D. M., and Buckley, H. R. (1994). Production of a hemolytic factor by Candida albicans. Infect. Immun. 62, 5154-5156.

Matzanke, B. F., Bill, E., Trautwein, A. X. and Winkelmann, G. (1987). Role of siderophores in iron storage in spores of Neurospora crassa and Aspergillus ochraceus. J. Bacteriol. 169, 5873-5876.

Mei, B., Budde, A. D., and Leong, S. A. (1993). sid1, a gene initiating siderophore biosynthesis in Ustilago maydis: molecular characterization, regulation by iron, and role in phytopathogenicity. Proc. Natl. Acad. Sci. U.S.A. 90, 903-907.

Miethke, M., and Marahiel, M. A. (2007) Siderophore-based iron acquisition and pathogen control. Microbiol. Mol. Biol. Rev. 71, 413-451.

Moroz, O. V., Antson, A. A., Grist, S. J., Maitland, N. J., Dodson, G. G., Wilson, K. S., Lukanidin, E., and Bronstein, I. B. (2003). Structure of the human S100A12-copper complex: implications for host-parasite defence. Acta Crystallogr. D Biol. Crystallogr. 59, 859-867.

Neilands, J. B. (1993). Siderophores. Arch. Biochem. Biophys. 302, 1-3.

Neilands, J.B., Konopka, K.,Schwyn, B., Coy, M., Francis, R. T., Paw, B. H., and Bagg, A. (1987). "Comparative biochemistry of microbial iron assimilation," in Iron Transport in Microbes, Plants and Animals, eds G. Winkelmann, D. Van der Helm, and J. B. Neilands (New York: VCH Publishers), 3-34.

Nyhus, K. J., and Jacobson, E. S. (1999). Genetic and physiologic characterization of ferric/cupric reductase constitutive mutants of Cryptococcus neoformans. Infect. Immun. 67, 2357-2365.

Pao, S. S., Paulsen, I. T., and Saier, M. H. Jr. (1998). Major facilitator superfamily. Microbiol. Mol. Biol. Rev. 62, 1-34.
Pena, M. M., Puig, S., and Thiele, D. J. (2000). Characterization of the Saccharomyces cerevisiae high affinity copper transporter Ctr3.J. Biol. Chem. 275, 33244-33251.

Pendrak, M. L., Chao, M. P., Yan, S. S., and Roberts, D. D. (2004). Heme oxygenase in Candida albicans is regulated by hemoglobin and is necessary for metabolism of exogenous heme and hemoglobin to alpha-biliverdin. J. Biol. Chem. 279, 3426-3433.

Philpott, C. C. (2006). Iron uptake in fungi: a system for every source. Biochim. Biophys. Acta 1763, 636-645.

Philpott, C. C., and Protchenko, O. (2008). Response to iron deprivation in Saccharomyces cerevisiae. Eukaryot. Cell 7, 20-27.

Puig, S., Lee, J., Lau, M., and Thiele, D. J. (2002). Biochemical and genetic analyses of yeast and human high affinity copper transporters suggest a conserved mechanism for copper uptake. J. Biol. Chem. 277, 26021-26030.

Rees, E. M., Lee, J., and Thiele, D. J. (2004). Mobilization of intracellular copper stores by the ctr2 vacuolar copper transporter. J. Biol. Chem. 279, 54221-54229.

Schaible, U. E., and Kaufmann, S. H. (2004). Iron and microbial infection. Nat. Rev. Microbiol. 2, 946-953.

Schrettl, M., Bignell, E., Kragl, C., Joechl, C., Rogers, T., Arst, H. N. Jr., Haynes, K., and Haas, H. (2004). Siderophore biosynthesis but not reductive iron assimilation is essential for Aspergillus fumigatus virulence. J. Exp. Med. 200, 1213-1219.

Schrettl, M., Bignell, E., Kragl, C., Sabiha, Y., Loss, O., Eisendle, M., Wallner, A., Arst, H. N. Jr., Haynes, K., and Haas, H. (2007). Distinct roles for intra- and extracellular siderophores during Aspergillus fumigatus infection. PLoS Pathog. 3, 1195-1207. doi: 10.1371/ journal.ppat.0030128

Shatwell, K. P., Dancis, A., Cross, A. R., Klausner, R. D., and Segal, A. W. (1996). The FRE1 ferric reductase of Saccharomyces cerevisiae is a cytochrome b similar to that of NADPH oxidase. J. Biol. Chem. 271, 14240-14244.

Stearman, R., Yuan, D. S., YamaguchiIwai, Y., Klausner, R. D., and Dancis, A. (1996). A permease-oxidase complex involved in high-affinity iron uptake in yeast. Science 271, 1552-1557.

Tangen, K. L., Jung, W. H., Sham, A. P., Lian, T., and Kronstad, J. W. (2007). The iron- and cAMP-regulated gene SIT1 influences ferrioxamine B utilization, melanization and cell wall structure in Cryptococcus neoformans. Microbiology 153, 29-41.

Timmerman, M. M., and Woods, J. P. (2001). Potential role for extracellular glutathione-dependent ferric 
reductase in utilization of environmental and host ferric compounds by Histoplasma capsulatum. Infect. Immun. 69, 7671-7678.

Van der Helm, D., and Winkelmann, G. (1994). "Hydroxamates and polycarbonates as iron transport agents (siderophores) in fungi," in Metal Ions in Fungi, eds G. Winkelmann and D. R. Winge (New York: Marcel Dekker), 39-148.

Van Ho, A., Ward, D. M., and Kaplan, J. (2002). Transition metal transport in yeast. Annu. Rev. Microbiol. 56, 237-261.

Waterman, S. R., Hacham, M., Hu, G., Zhu, X., Park, Y. D., Shin, S., Panepinto, J., Valyi-Nagy, T., Beam, C., Husain, S., Singh, N., and Williamson, P. R. (2007). Role of a CUF1/CTR4 copper regulatory axis in the virulence of Cryptococcus neoformans. J. Clin. Invest. 117, 794-802.

Weinberg, E. D. (2009). Iron availability and infection. Biochim. Biophys. Acta 1790, 600-605.

Weissman, Z., Shemer, R., Conibear, E., and Kornitzer, D. (2008). An endocytic mechanism for haemoglobin-iron acquisition in Candida albicans. Mol. Microbiol. 69, 201-217.
Winters, M. S., Chan, Q., Caruso, J. A., and Deepe, G.S. Jr. (2010). Metallomic analysis of macrophages infected with Histoplasma capsulatum reveals a fundamental role for zinc in host defenses. J. Infect. Dis. 202, 1136-1145.

Wu, C. Y., Bird, A. J., Chung, L. M., Newton, M.A.,Winge,D.R., and Eide, D. J. (2008). Differential control of Zapl-regulated genes in response to zinc deficiency in Saccharomyces cerevisiae. BMCGenomics 9, 370. doi: 10.1186/1471-2164-9-370

Yuan, D. S., Dancis, A., and Klausner, R. D. (1997). Restriction of copper export in Saccharomyces cerevisiae to a late Golgi or post-Golgi compartment in the secretory pathway. J. Biol. Chem. 272, 25787-25793.

Yun, C. W., Ferea, T., Rashford, J., Ardon, O., Brown, P. O., Botstein, D., Kaplan, J., and Philpott, C. C. (2000a). Desferrioxamine-mediated iron uptake in Saccharomyces cerevisiae. Evidence for two pathways of iron uptake. J. Biol. Chem. 275, 10709-10715.

Yun,C.W., Tiedeman,J.S.,Moore, R.E., and Philpott, C. C. (2000b). Siderophoreiron uptake in Saccharomyces cerevisiae. Identification of ferrichrome and fusarinine transporters. J. Biol. Chem. 275, 16354-16359.
Zarnowski, R., and Woods, J. P. (2005). Glutathione-dependent extracellular ferric reductase activities in dimorphic zoopathogenic fungi. Microbiology 151, 2233-2240.

Zhang, Y., Lyver, E. R., Knight, S. A. Pain, D., Lesuisse, E., and Dancis, A. (2006). Mrs3p, Mrs4p, and frataxin provide iron for Fe-S cluster synthesis in mitochondria. J. Biol. Chem. 281, 22493-22502.

Zhao, H., and Eide, D. (1996a). The yeast ZRT1 gene encodes the zinc transporter protein of a high-affinity uptake system induced by zinc limitation. Proc. Natl. Acad. Sci. U.S.A. 93, 2454-2458.

Zhao, H., and Eide, D. (1996b). The ZRT2 gene encodes the low affinity zinc transporter in Saccharomyces cerevisiae. J. Biol. Chem. 271, 23203-23210.

Zhao, H., and Eide, D. J. (1997). Zaplp, a metalloregulatory protein involved in zinc-responsive transcriptional regulation in Saccharomyces cerevisiae. Mol. Cell. Biol. 17, 5044-5052.

Conflict of Interest Statement: The authors declare that the research was conducted in the absence of any commercial or financial relationships that could be construed as a potential conflict of interest.

Received: 20 August 2010; accepted: 03 March 2011; published online: 21 March 2011.

Citation: Silva MG, Schrank A, Bailão EFLC, Bailão AM, Borges CL, Staats CC, Parente JA, Pereira M, Salem-Izacc SM, Mendes-Giannini MJS, Oliveira RMZ, Rosa e Silva LK, Nosanchuk JD, Vainstein MH and Soares CMA (2011) The homeostasis of iron, copper, and zinc in Paracoccidioides brasiliensis, Cryptococcus neoformans var. grubii, and Cryptococcus gattii: a comparative analysis. Front. Microbio. 2:49. doi: 10.3389/fmicb.2011.00049

This article was submitted to Frontiers in Fungi and Their Interactions, a specialty of Frontiers in Microbiology.

Copyright (c) 2011 Silva, Schrank, Bailão, Bailão, Borges, Staats, Parente, Pereira, Salem-Izacc, Mendes-Giannini, Oliveira, Rosa e Silva, Nosanchuk, Vainstein and Soares. This is an open-access article subject to an exclusive license agreement between the authors and Frontiers Media $S A$, which permits unrestricted use, distribution, and reproduction in any medium, provided the original authors and source are credited. 


\section{APPENDIX}

Table A1 | Conserved domains in proteins involved in iron, copper and zinc uptake by reductive systems in P. brasiliensis isolates and Cryptococcus species.

\begin{tabular}{|c|c|c|c|c|c|}
\hline Gene product & Predicted function & Organism/accession number ${ }^{\dagger}$ & Conserved domains* & $\begin{array}{l}\text { Transmembrane } \\
\text { domains* }\end{array}$ & Signal peptide* \\
\hline \multirow[t]{2}{*}{ Fre1 } & Metalloreductase & P. brasiliensis 01/PAAG_05370.1 & Ferric reductase domain & 7 & Yes \\
\hline & & & NAD-binding domain & & \\
\hline \multirow[t]{2}{*}{ Fre3 } & Metalloreductase & P. brasiliensis 01/PAAG_02079.1 & Ferric reductase domain & 6 & Yes \\
\hline & & P. brasiliensis 18/PADG_00813.1 & NAD-binding domain & 6 & Yes \\
\hline \multirow[t]{3}{*}{ Fre5 } & Metalloreductase & P. brasiliensis 03/PABG_07812.1 & Ferric reductase domain & 6 & No \\
\hline & & & FAD-binding domain & & \\
\hline & & & NAD-binding domain & & \\
\hline \multirow[t]{3}{*}{ Fre7 } & Metalloreductase & P. brasiliensis 01/PAAG_06164.1 & & 8 & No \\
\hline & & C. neoformans/CNAG_00876.2 & NAD-binding domain & 7 & No \\
\hline & & C. gattii/CNBG_6082.2 & & 8 & No \\
\hline \multirow[t]{3}{*}{ Fre8 } & Metalloreductase & C. neoformans/CNAG_07334.2 & Ferric reductase domain & 6 & No \\
\hline & & & FAD-binding domain & & \\
\hline & & C. gattii/CNBG_2116.2 & NAD-binding domain & 6 & No \\
\hline \multirow[t]{3}{*}{ Fre10 } & Metalloreductase & C. neoformans/CNAG_06821.2 & Ferric reductase domain & 4 & No \\
\hline & & & FAD-binding domain & & \\
\hline & & C. gattii/CNBG_5888.2 & NAD-binding domain & 4 & No \\
\hline $\mathrm{Cfl} 4$ & Metalloreductase & C. neoformans/CNAG_06524.2 & Ferric reductase domain & 5 & No \\
\hline \multirow[t]{4}{*}{ Fet5 } & Ferroxidase & P. brasiliensis 03/PABG_05667.1 & Copper-oxidase domain & - & No \\
\hline & & P. brasiliensis 18/PADG_05994.1 & & - & No \\
\hline & & C. neoformans/CNAG_07865.2 & & 1 & Yes \\
\hline & & C. gattii/CNBG_4942.2 & & 1 & Yes \\
\hline \multirow[t]{2}{*}{ Fet31 } & Ferroxidase & P. brasiliensis 01/PAAG_06004.1 & Copper-oxidase domain & 1 & No \\
\hline & & C. neoformans/CNAG_02958.2 & & - & Yes \\
\hline \multirow[t]{2}{*}{ Fet33 } & Ferroxidase & P. brasiliensis 01/PAAG_00163.1 & Copper-oxidase domain & - & No \\
\hline & & P. brasiliensis 03/PABG_05183.1 & & - & Yes \\
\hline \multirow[t]{2}{*}{ Ftr1/Ftr2 } & Iron permease & C. neoformans/CNAG_06242.2 & FTR1 domain & 7 & Yes \\
\hline & & C. gattii/CNBG_3602.2 & & 6 & Yes \\
\hline \multirow[t]{2}{*}{ Fth1 } & Iron permease & C. neoformans/CNAG_02959.2 & FTR1 domain & 7 & Yes \\
\hline & & C. gattii/CNBG_4943.2 & & 7 & Yes \\
\hline
\end{tabular}


Table A1 | Continued

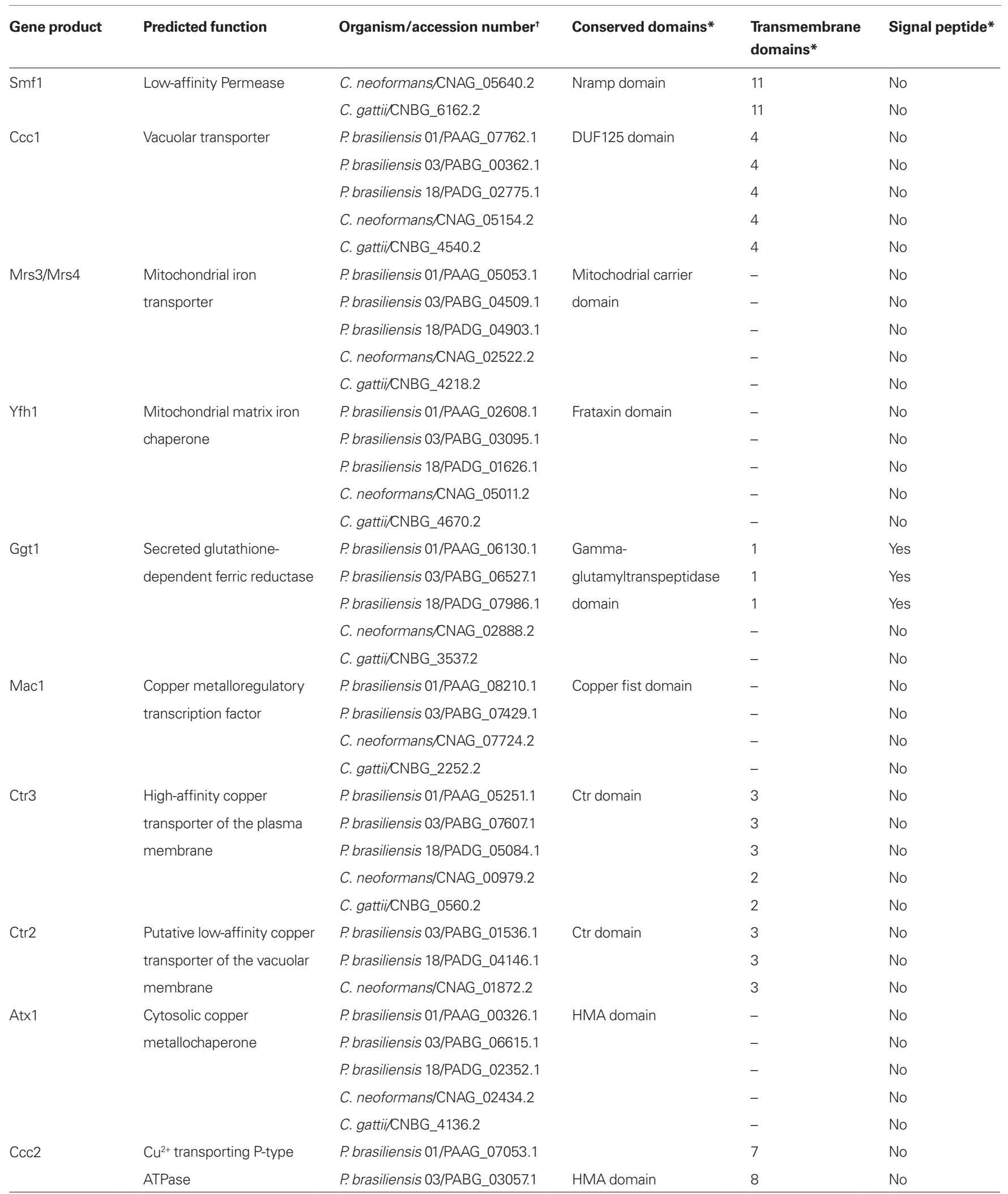


Table A1 | Continued

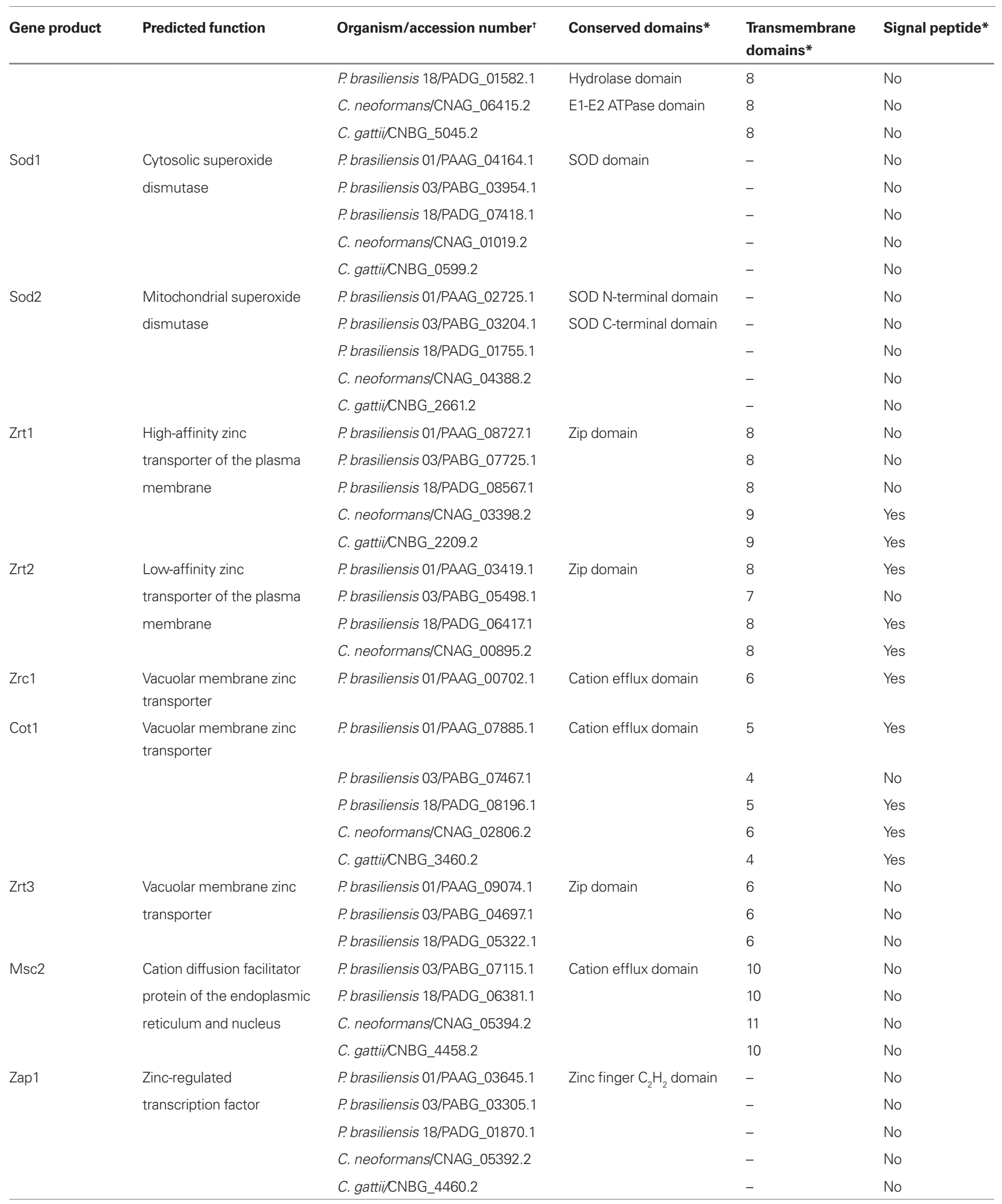

*Amino acid sequence analysis was performed using the online software SMART.

${ }^{\dagger}$ Accession numbers: PAAG refers to Pb01; PABG refers to Pb03; PADG refers to Pb18; CNAG refers to C. neoformans var. grubii and CNBG refers to C. gattii. 
Table A2 | Conserved domains in proteins related to siderophore biosynthesis and to iron uptake by the non-reductive siderophore transport system in $P$. brasiliensis isolates and Cryptococcus species.

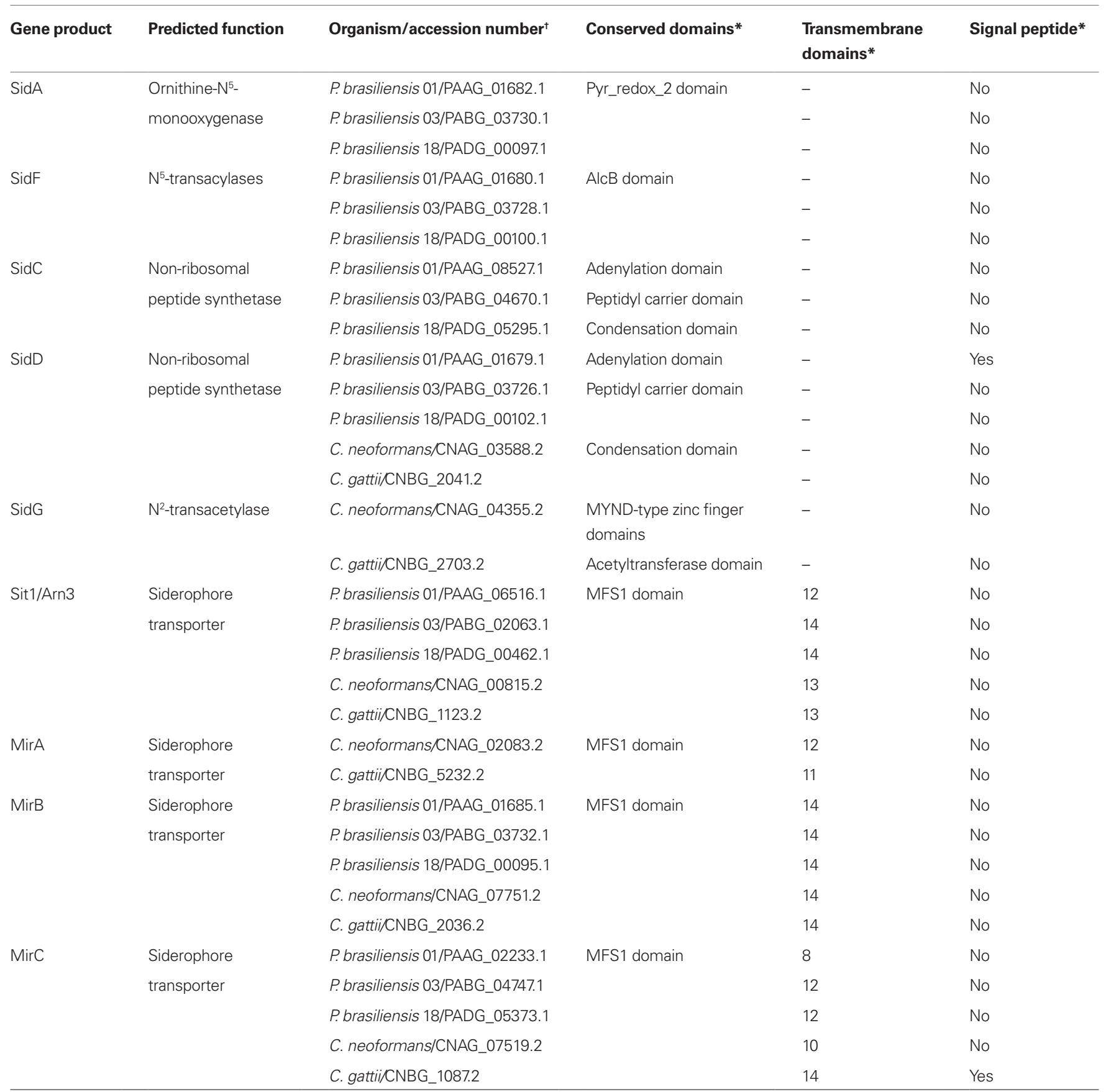

*Amino acid sequence analysis was performed using the online software SMART.

${ }^{+}$Accession numbers: PAAG refers to Pb01; PABG refers to Pb03; PADG refers to Pb18; CNAG refers to $C$. neoformans var. grubii and $C N B G$ refers to $C$. gattii. 